\title{
Bizarre Waveforms in Strong Motion Records
}

\author{
Baofeng Zhou, ${ }^{1,2,3}$ Haiyun Wang, ${ }^{2}$ Lili Xie, ${ }^{1,3}$ and Yanru Wang ${ }^{4,5}$ \\ ${ }^{1}$ Institute of Engineering Mechanics, China Earthquake Administration, Harbin 150080, China \\ ${ }^{2}$ Heilongjiang Construction Group, Harbin 150080, China \\ ${ }^{3}$ Harbin Institute of Technology, Harbin 150080, China \\ ${ }^{4}$ Wenzhou University, Wenzhou 325035, China \\ ${ }^{5}$ Tongji University, Shanghai 200092, China \\ Correspondence should be addressed to Baofeng Zhou; zbf166@126.com
}

Received 3 March 2015; Accepted 27 May 2015

Academic Editor: Yanxue Wang

Copyright (C) 2015 Baofeng Zhou et al. This is an open access article distributed under the Creative Commons Attribution License, which permits unrestricted use, distribution, and reproduction in any medium, provided the original work is properly cited.

\begin{abstract}
This paper collects a rich set of strong motion records in some typical earthquakes domestic and abroad, checks its seismic events, converts the data format, corrects the zeroline and draws the waveform. Four kinds of abnormal phenomena on the acceleration waveform are revealed, such as spike, asymmetric waveform, obvious baseline drift, and strong motion records packets separation. Then reasonable processing approaches are derived from the preliminary analysis of the generation mechanism for abnormal phenomena. In addition to the effects on time history, Fourier amplitude spectrum and response spectrum are studied before and after strong motion records correction. It is shown that (1) mechanism of spikes is rather complicated; however spikes can be eliminated by "jerk" method, ratio method, and the consistency of the three-component PGA time; (2) mechanism of the asymmetric waveform is of diversity; however, to some extent, the Butterworth low-pass filtering can be applied to correct it; (3) two pieces of strong motion record packets can be connected by searching continuous and repeated data; (4) the method of cumulative adding can be used to find the clear baseline drift; (5) the abnormal waveform directly affects the characteristics of time history and frequency spectrum.
\end{abstract}

\section{Introduction}

Strong motion records obtained from strong motion accelerometers are the first-hand data for the study of strong ground motion, which are precious indeed. However, there are some abnormal data in a few strong motion records, which reduces the application confidence of the observed data. If they are not corrected, these records could hardly reveal the correlated information of the structure or the ground motion under some earthquakes and thus affect the conclusion of the following scientific research. For example, if such data are used in the ground motion attenuation study, the shape of the instruments seismic intensity would possibly be altered and accordingly would mislead the emergency rescue and disaster evaluation. As a result, the research on the abnormal waveform in strong motion records is of great significance. Its fundamental objective is to eliminate the false information therein and warn the researchers against the distorted waves in the process of selecting seismic waves.
At present, abnormal waves have attracted much attention of scientists; however, the domestic and abroad studies on abnormal waves are relatively scarce. For example, Wen et al. [1] conducted a study on the reasons for the abnormal waves of PGA (peak ground acceleration) over $1 \mathrm{~g}$ in the east-west direction of acceleration record belonging to the station coded TCU129 in "9.21 Chi-Chi" earthquake. Zhou et al. [2] probed the abnormal record caused by the pillars in Yibin Gaochang station in Wenchuan earthquake. The Science journal attributed the asymmetry waves to "trampoline effect" [3]. Douglas [4] classified the records according to the recorded wave quality, holding that some of the accelerated records, influenced by the nonstandardization and digitization, could hardly be used in the research of seismic motion. This phenomenon is common for both analog records and the digital records. These abnormal waves can hardly be corrected by filter techniques or baseline correction to erase the low-frequency and high-frequency noises. Considering 
that the strong motion data is of great significance for the earthquake engineering, the research on the mechanism of abnormal records, therefore, appears particularly important. This study summarized the abnormal records as follows: there are four abnormal waves in the strong motion records, as they are "spike," "asymmetric waveforms," strong motion record separation, and obvious baseline translation. Moreover, the mechanism for the generation of abnormal records is analyzed based on the characteristics of time history and frequency spectrum. Finally, processing methods to correct abnormal records are proposed.

\section{On the "Spike"}

An obvious "spike" is attributed to the unreasonable peak value [5-9] in the acceleration time history. Spike, according to its English explanation, is something long and thin with a sharp point. The high-frequency "spike," which usually pops up in the acceleration time history, is an isolated data point incompatible with the neighboring data points. If used in the earthquake engineering research, the objective of the research findings will be endangered. As a result, it is necessary to discriminate and dispose properly of the data abnormal values. The reasons for the abnormality should be analyzed: if it is caused by the earthquake source mechanism or travel path, it should be kept; otherwise, necessary adjustments should be made based on respective study objectives, and the abnormal points should be replaced by the reasonable and reliable data, in order not to have negative effect on the relevant research. Generally, the "spike" can be further classified into two types: the first type can be called simple "spike," as they often appear in the beginning or the end of a record, and they are easier to detect by visual observation. And the other type can be called complicated "spike," as they are hidden in the PGA of complicated waveforms and are hard to discriminate and hazardous.

2.1. On the Simple "Spike". The simple "spike" can be detected visually. As illustrated in Figure 1, in the NS direction of record 20050110234857_4805 in Turkey strong motion database, the projected line in the red circle is a "spike." Its value of amplitude reaches $-7.79 \mathrm{~cm} / \mathrm{s}^{2}$, which is several hundred times of that of the neighboring waves. It is incompatible with the neighboring waves and can hardly be justified physically. Figure 2 shows the acceleration time history of 051HSD080628022001, the aftershock of Wenchuan earthquake. An obvious "spike" appears in the rear part of time history, which is incompatible with the neighboring waves and easy to discern.

According to Bommer and Boore [7], a spike can be discerned in this way: if there is a spike in the acceleration, and a "jerk" time history produces with the differential of acceleration, whose unilateral pulse becomes the bilateral pulse. The phenomenon of "spike" occurs in the "5.12" Wenchuan earthquake mainshock in 2008. Taking the example of the two records, 032XPX080512142802 and 062WIX080512142801 [10], their acceleration and "jerk" time history are shown in Figures 3 and 4. Though the PGA in

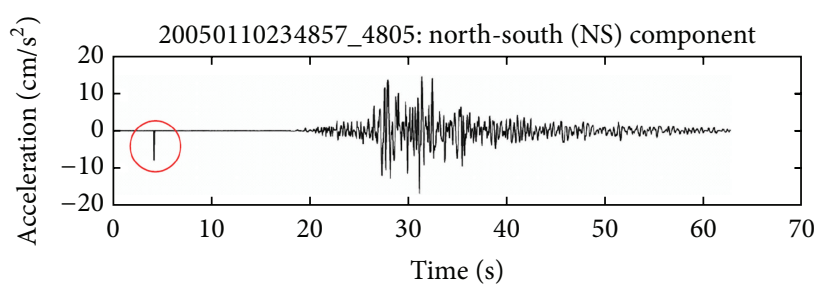

Figure 1: A "spike" in the beginning.

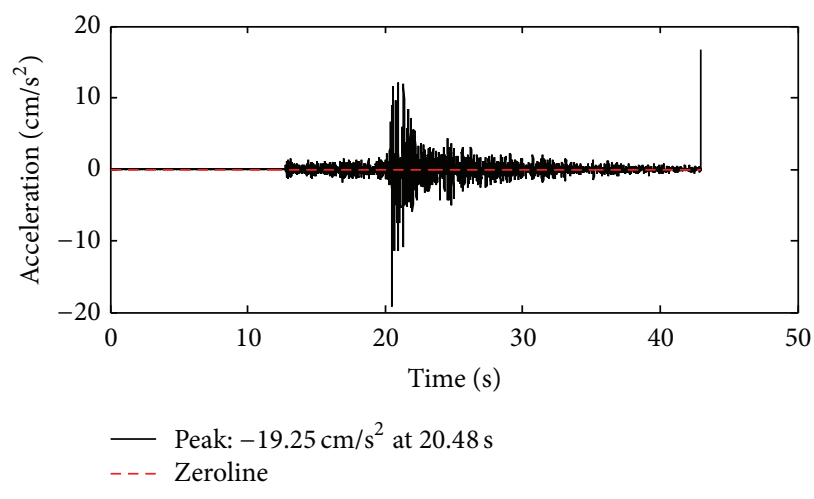

Figure 2: A "spike" in the end.

032XPX080512142802 is relatively small, it still holds true. The "spike," with unilateral pulse in acceleration, turns into a "jerk" with bilateral pulse, so the PGA is confirmed as a "spike."

2.2. On the Complex "Spike". When earthquakes occur, observed data is in dynamic and continuous change, which will exceed the scope of the mutation confronted with abnormal situation. So spike can be recognized with the ratio of PGA to adjacent data. Strong motion records of the 1999 Chi-Chi, Taiwan, Mw7.6 earthquake [11], 2010 Christchurch, Mw7.0 earthquake, and 2011 Mw6.3 earthquake in New Zealand [12] are selected when PGA is greater than 20 gal. Then statistics is carried out on the ratio of the PGA to adjacent sampling points value, but it should be assumed that the adjacent data is reliable without any distortion, and the ratio is unlikely to be much higher normally.

It is recognized by the world that the quality of Taiwan "9.21 Chi-Chi" earthquake strong motion records is very high. Therefore, 1269 pieces of records are selected to make statistical ratio of the PGA to adjacent sampling value, including 481 of the EW direction, 498 of the NS direction, and 290 of the UD direction [10]. We find that the level of the ratio of more than 1.1 is less than $1 \%$ in the horizontal components and less than $5 \%$ in the vertical components, which indicates that the ratio of more than 1.1 is a small probability event. Table 1 presents a summary of the ground motions with ratio exceeding 1.1, wherein "LPGA" stands for the ratio of PGA to the left adjacent sampling point, and "RPGA" is the ratio of PGA to the right adjacent sampling point. Figure 5 illustrates the acceleration time history of the record named KAU022_N.SAC whose ratios are beyond 4, so 

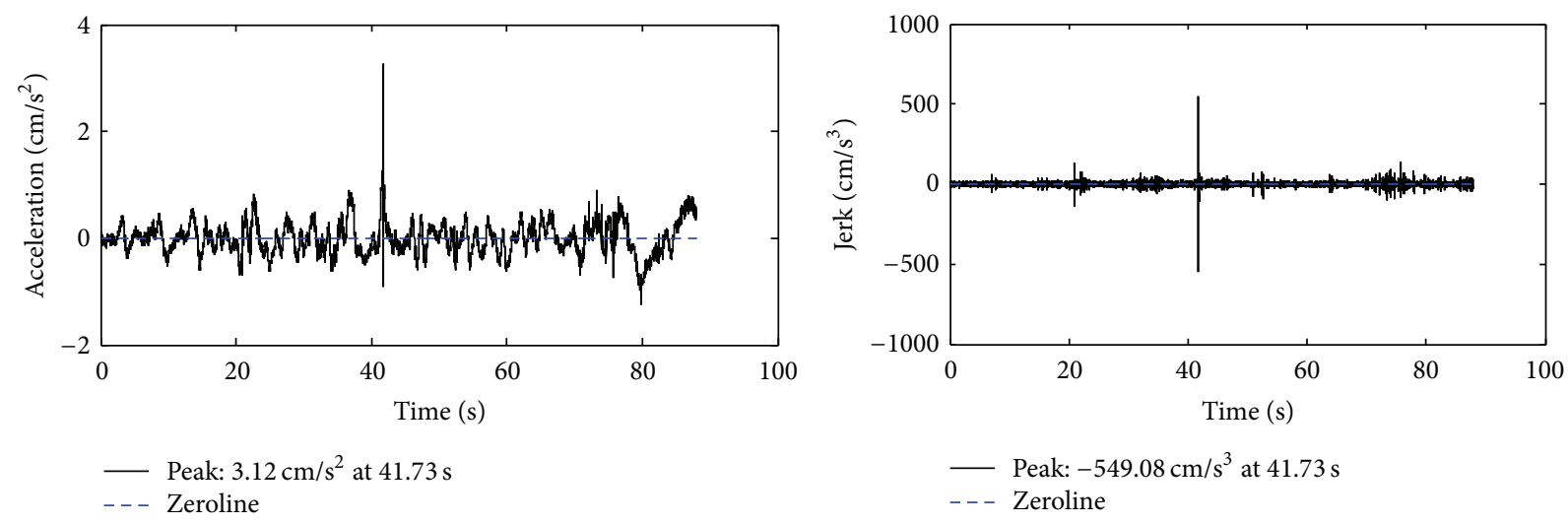

FIgURE 3: Acceleration time history and Jerk time history (032XPX080512142802).
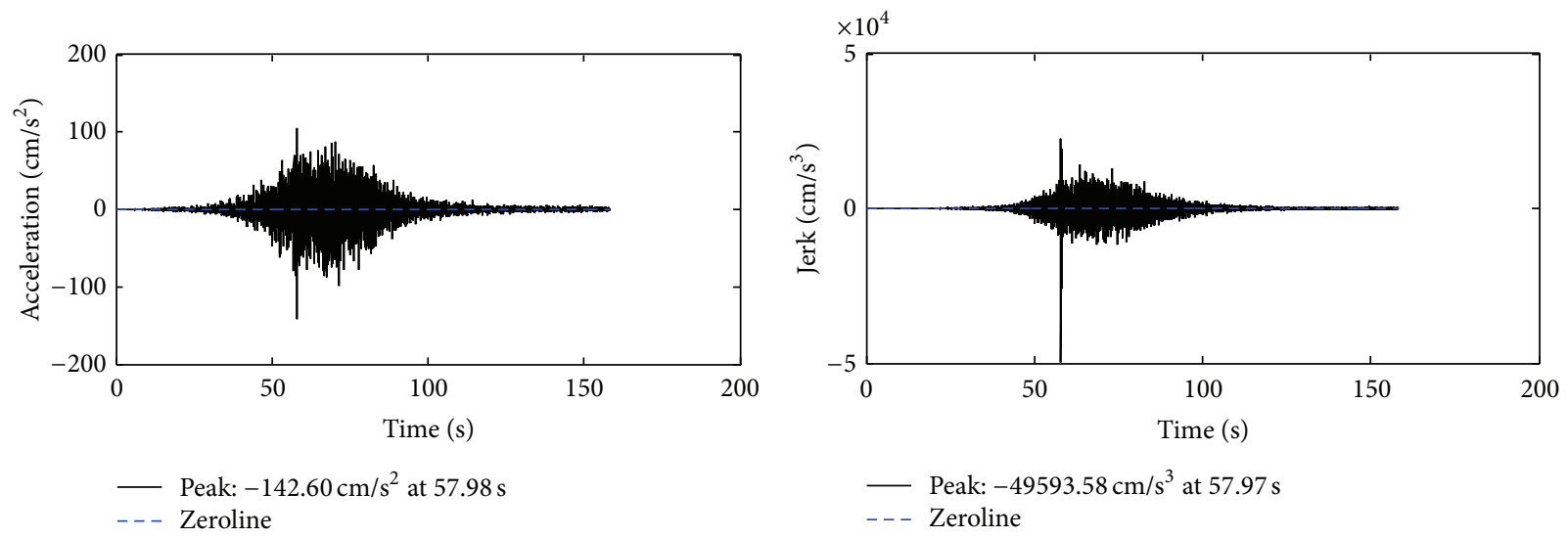

FIGURE 4: Acceleration time history and Jerk time history (062WIX080512142801).

the PGA point can be determined as "spike" because of the obvious discordant with the surrounding waveform.

Mw7.0 and Mw6.3 earthquakes are studied in New Zealand by applying the ratio method. For Mw7.0 earthquake, there are 153 strong motion records including 55 of EW direction, 55 of NS direction, and 43 of UD direction. It is found that the ratio greater than 1.1 does not exceed 5\% in the horizontal components; however, the ratio greater than 1.1 is more than $26 \%$ in the vertical direction. From Table 2, all ratios are greater than 0 , and the maximum ratio is 2.75 coming from NZOXZ.raw. For Mw6.3 earthquake, there are 128 pieces of strong motion records including 44 of EW direction, 46 of NS direction, and 38 of UD direction. It is found that the ratio greater than 1.1 does not exceed 5\% in the horizontal components; however, the ratio greater than 1.1 is in excess of $25 \%$ in the vertical components. As shown in Table 3, all ratios are greater than 0 , and the maximum ratio reaches 6.69 for the record named NZMQZ.raw. Representative waveform diagrams are shown in Figures 6-9, of which PGA can be deemed as "spike" [13].

In addition, the "spike" can be identified according to the time where the three-component PGA occurs. As shown in Figure 10, taking the three-component records from Rushan Ms4.3 earthquake in 2014 as an example, the time

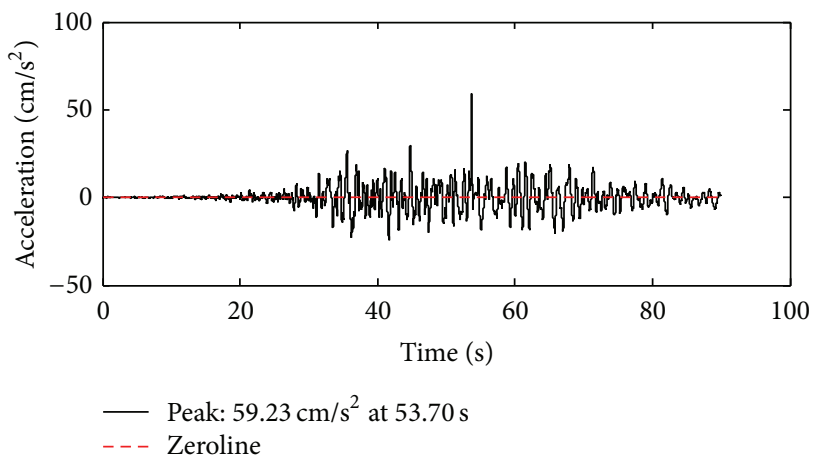

FIGURE 5: Acceleration time history (KAU022_N.SAC, ratl = 4.48, ratr $=4.48)$.

for PGA is $12.08 \mathrm{~s}, 13.70 \mathrm{~s}$, and $13.66 \mathrm{~s}$ in UD, EW, and NS direction, respectively, and the time for PGA of the vertical component is ahead of more than $1.5 \mathrm{~s}$ compared with the horizontal component. Furthermore, PGA is 29.5 times of the former sampling point value and 2.19 times of the next sampling point value. Therefore, the PGA can be considered as "spike" in the UD direction. In addition, the "spike" can 
TABLE 1: Records with ratio of PGA to adjacent points greater than 1.1 in Chi-Chi earthquake.

(a)

\begin{tabular}{|c|c|c|c|c|c|c|c|}
\hline Serial number & Filename & PGA $\left(\mathrm{cm} / \mathrm{s}^{2}\right)$ & Time (s) & $\operatorname{LPGA}\left(\mathrm{cm} / \mathrm{s}^{2}\right)$ & Left rate & RPGA $\left(\mathrm{cm} / \mathrm{s}^{2}\right)$ & Right rate \\
\hline 1 & CHY028_E.SAC & -626.71 & 37.92 & -615.82 & 1.02 & -507.73 & 1.23 \\
\hline 2 & CHY028.E.SAC & -36.89 & 25.83 & -33.06 & 1.12 & -28.76 & 1.28 \\
\hline 3 & TCU088.E.SAC & 60.29 & 12.24 & 57.00 & 1.06 & 50.60 & 1.19 \\
\hline 4 & CHY082.Z.SAC & 30.79 & 22.18 & 30.73 & 1.00 & 27.92 & 1.10 \\
\hline 5 & TCU056.Z.SAC & 25.60 & 27.12 & 22.61 & 1.13 & 24.64 & 1.04 \\
\hline 6 & TCU071.Z.SAC & -140.09 & 26.41 & -127.23 & 1.10 & -138.71 & 1.01 \\
\hline 7 & TCU078.Z.SAC & 219.87 & 24.85 & 214.85 & 1.02 & 183.26 & 1.20 \\
\hline 8 & TCU079.Z.SAC & 160.21 & 25.31 & 127.91 & 1.25 & 156.20 & 1.03 \\
\hline 9 & CHY028_N.SAC & -748.58 & 36.19 & -745.89 & 1.00 & -615.31 & 1.22 \\
\hline 10 & KAU022_N.SAC & 59.23 & 53.70 & 13.23 & 4.48 & 13.23 & 4.48 \\
\hline 11 & TCU045_N.SAC & 511.68 & 44.86 & 462.57 & 1.11 & 438.28 & 1.17 \\
\hline 12 & TCU071_N.SAC & -638.90 & 32.01 & -550.32 & 1.16 & -637.53 & 1.00 \\
\hline 13 & CHY028.N.SAC & 43.29 & 25.80 & 40.12 & 1.08 & 37.37 & 1.16 \\
\hline 14 & TCU048.N.SAC & -30.71 & 21.19 & -27.90 & 1.10 & -28.08 & 1.09 \\
\hline 15 & TCU088.N.SAC & 53.73 & 12.28 & 42.42 & 1.27 & 43.86 & 1.23 \\
\hline 16 & TCU067.E.SAC & -164.30 & 32.61 & -142.52 & 1.15 & -163.46 & 1.01 \\
\hline 17 & TCU079.E.SAC & -330.53 & 26.58 & -215.92 & 1.53 & -325.56 & 1.02 \\
\hline 18 & CHY028_Z.SAC & 335.49 & 35.26 & 274.42 & 1.22 & 293.62 & 1.14 \\
\hline 19 & CHY032_Z.SAC & -61.78 & 39.62 & -61.66 & 1.00 & -56.09 & 1.10 \\
\hline 20 & CHY036_Z.SAC & 104.33 & 30.29 & 93.39 & 1.12 & 98.41 & 1.06 \\
\hline 21 & CHY041_Z.SAC & -122.85 & 39.18 & -111.06 & 1.11 & -119.80 & 1.03 \\
\hline 22 & CHY082_Z.SAC & -78.37 & 41.04 & -69.45 & 1.13 & -77.11 & 1.02 \\
\hline 23 & HWA007_Z.SAC & -30.00 & 27.12 & -26.35 & 1.14 & -29.58 & 1.01 \\
\hline 24 & HWA032_Z.SAC & -87.36 & 39.32 & -76.06 & 1.15 & -85.98 & 1.02 \\
\hline
\end{tabular}

(b)

\begin{tabular}{|c|c|c|c|c|c|c|c|}
\hline Serial number & Filename & PGA $\left(\mathrm{cm} / \mathrm{s}^{2}\right)$ & Time (s) & LPGA $\left(\mathrm{cm} / \mathrm{s}^{2}\right)$ & Left rate & RPGA $\left(\mathrm{cm} / \mathrm{s}^{2}\right)$ & Right rate \\
\hline 25 & TAP042_Z.SAC & -24.15 & 53.71 & -9.26 & 2.61 & -8.42 & 2.87 \\
\hline 26 & TCU039_Z.SAC & 121.91 & 44.81 & 119.52 & 1.02 & 109.47 & 1.11 \\
\hline 27 & TCU045_Z.SAC & -353.17 & 44.82 & -324.69 & 1.09 & -292.03 & 1.21 \\
\hline 28 & TCU074_Z.SAC & 270.16 & 37.64 & 245.45 & 1.10 & 255.86 & 1.06 \\
\hline 29 & TCU076_Z.SAC & -275.44 & 28.24 & -272.27 & 1.01 & -237.88 & 1.16 \\
\hline 30 & TCU078_Z.SAC & 170.98 & 27.34 & 163.62 & 1.05 & 154.05 & 1.11 \\
\hline 31 & TCU089_Z.SAC & 190.13 & 41.01 & 159.14 & 1.19 & 183.37 & 1.04 \\
\hline 32 & TCU103_Z.SAC & 142.29 & 33.93 & 128.89 & 1.10 & 129.91 & 1.10 \\
\hline 33 & TCU109_Z.SAC & -133.03 & 28.17 & -129.62 & 1.03 & -119.46 & 1.11 \\
\hline 34 & TCU112_Z.SAC & -65.26 & 40.32 & -58.02 & 1.12 & -65.20 & 1.00 \\
\hline 35 & TCU118_Z.SAC & 98.79 & 42.15 & 97.89 & 1.01 & 87.48 & 1.13 \\
\hline 36 & TCU122_Z.SAC & 236.03 & 33.58 & 213.77 & 1.10 & 218.38 & 1.08 \\
\hline 37 & HWA032.Z.SAC & 23.67 & 21.50 & 20.92 & 1.13 & 22.00 & 1.08 \\
\hline 38 & TCU051.Z.SAC & -30.08 & 21.11 & -29.72 & 1.01 & -27.09 & 1.11 \\
\hline 39 & TCU055.Z.SAC & -50.62 & 6.07 & -49.84 & 1.02 & -45.47 & 1.11 \\
\hline 40 & TCU071.Z.SAC & 26.11 & 22.51 & 23.54 & 1.11 & 26.05 & 1.00 \\
\hline 41 & TCU076.Z.SAC & -35.93 & 13.73 & -32.10 & 1.12 & -33.66 & 1.07 \\
\hline 42 & TCU079.Z.SAC & -260.84 & 14.39 & -254.38 & 1.03 & -225.01 & 1.16 \\
\hline 43 & TCU106.Z.SAC & -26.92 & 13.65 & -22.61 & 1.19 & -25.36 & 1.06 \\
\hline 44 & TCU117.Z.SAC & -20.52 & 11.33 & -18.61 & 1.10 & -19.68 & 1.04 \\
\hline 45 & TCU118.Z.SAC & -20.02 & 34.33 & -19.96 & 1.00 & -17.45 & 1.15 \\
\hline 46 & CHY027.Z.SAC & 23.86 & 21.42 & 20.99 & 1.14 & 21.95 & 1.09 \\
\hline 47 & CHY032.Z.SAC & -30.16 & 22.00 & -25.38 & 1.19 & -27.47 & 1.10 \\
\hline
\end{tabular}


TABLE 2: Records with ratio of PGA to adjacent points greater than 1.1 in New Zealand Mw7.0 earthquake.

\begin{tabular}{|c|c|c|c|c|c|c|c|}
\hline Serial number & Filename & PGA $\left(\mathrm{cm} / \mathrm{s}^{2}\right)$ & Time (s) & LPGA $\left(\mathrm{cm} / \mathrm{s}^{2}\right)$ & Left rate & RPGA $\left(\mathrm{cm} / \mathrm{s}^{2}\right)$ & Right rate \\
\hline 1 & NZGDLC.raw & 757.45 & 19.59 & 731.22 & 1.04 & 609.28 & 1.24 \\
\hline 2 & NZLPCC.raw & -351.17 & 24.71 & -307.16 & 1.14 & -345.18 & 1.02 \\
\hline 3 & NZOXZ.raw & -123.11 & 5.17 & -119.27 & 1.03 & -92.84 & 1.33 \\
\hline 4 & NZTPLC.raw & 293.60 & 26.88 & 264.31 & 1.11 & 280.44 & 1.05 \\
\hline 5 & NZLPCC.raw & -235.65 & 24.24 & -208.40 & 1.13 & -228.80 & 1.03 \\
\hline 6 & NZOXZ.raw & -143.11 & 8.21 & -105.39 & 1.36 & -89.06 & 1.61 \\
\hline 7 & NZROLC.raw & -383.66 & 23.11 & -351.29 & 1.09 & -339.79 & 1.13 \\
\hline 8 & NZTPLC.raw & 210.60 & 26.85 & 180.57 & 1.17 & 177.95 & 1.18 \\
\hline 9 & NZADCS.raw & 54.63 & 38.73 & 53.68 & 1.02 & 49.25 & 1.11 \\
\hline 10 & NZASHS.raw & -152.80 & 26.74 & -144.96 & 1.05 & -124.40 & 1.23 \\
\hline 11 & NZCBGS.raw & -120.85 & 28.69 & -114.03 & 1.06 & -99.33 & 1.22 \\
\hline 12 & NZCCCC.raw & 197.06 & 24.37 & 187.78 & 1.05 & 154.30 & 1.28 \\
\hline 13 & NZCMHS.raw & 290.53 & 28.59 & 257.07 & 1.13 & 255.86 & 1.14 \\
\hline 14 & NZCRLZ.raw & 89.77 & 28.95 & 88.81 & 1.01 & 75.57 & 1.19 \\
\hline 15 & NZDFHS.raw & 367.40 & 16.53 & 295.80 & 1.24 & 329.44 & 1.12 \\
\hline 16 & NZDORC.raw & 74.67 & 27.89 & 70.76 & 1.06 & 62.85 & 1.19 \\
\hline 17 & NZDSLC.raw & -311.99 & 21.34 & -285.78 & 1.09 & -282.37 & 1.10 \\
\hline 18 & NZGDLC.raw & 1234.74 & 19.97 & 1101.56 & 1.12 & 721.89 & 1.71 \\
\hline 19 & NZHORC.raw & 803.65 & 26.25 & 528.37 & 1.52 & 705.96 & 1.14 \\
\hline 20 & NZHPSC.raw & 136.27 & 25.00 & 133.20 & 1.02 & 119.93 & 1.14 \\
\hline 21 & NZHVSC.raw & 295.10 & 27.76 & 266.71 & 1.11 & 288.25 & 1.02 \\
\hline 22 & NZLINC.raw & 896.58 & 24.11 & 711.95 & 1.26 & 805.26 & 1.11 \\
\hline 23 & NZLPCC.raw & -154.05 & 21.24 & -133.39 & 1.15 & -148.35 & 1.04 \\
\hline 24 & NZLRSC.raw & 100.40 & 18.01 & 100.31 & 1.00 & 84.57 & 1.19 \\
\hline 25 & NZNNBS.raw & 146.64 & 28.64 & 128.06 & 1.15 & 134.41 & 1.09 \\
\hline 26 & NZOXZ.raw & 102.46 & 6.37 & 37.32 & 2.75 & 57.44 & 1.78 \\
\hline 27 & NZROLC.raw & 725.94 & 24.52 & 500.13 & 1.45 & 319.60 & 2.27 \\
\hline 28 & NZSMTC.raw & -228.36 & 22.72 & -159.43 & 1.43 & -210.30 & 1.09 \\
\hline 29 & NZSPFS.raw & 101.45 & 27.24 & 90.27 & 1.12 & 93.95 & 1.08 \\
\hline 30 & NZTPLC.raw & 860.73 & 26.90 & 375.54 & 2.29 & 857.08 & 1.00 \\
\hline 31 & NZTRCS.raw & 35.21 & 32.84 & 34.85 & 1.01 & 31.44 & 1.12 \\
\hline 32 & NZWSFC.raw & 64.51 & 28.66 & 54.87 & 1.18 & 61.15 & 1.05 \\
\hline
\end{tabular}

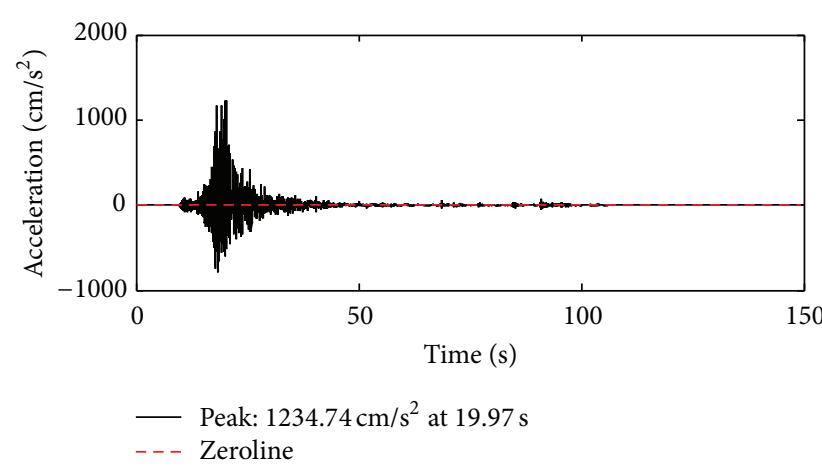

FIGURE 6: Acceleration time history (NZGDLC.raw, UP, ratl = 1.12, ratr $=1.71)$.

be identified according to the overall strong ground motion characterization in an earthquake [13].

2.3. Causes for the "Spike". There are many causes for a "spike," including the pendulum and recorder, sudden

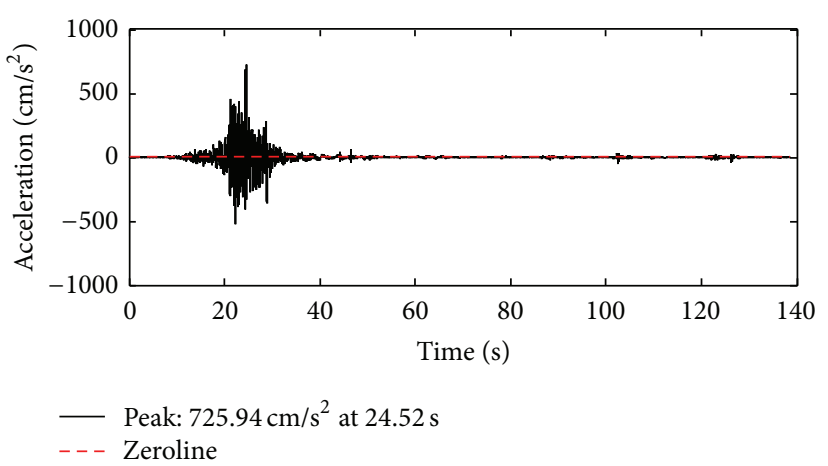

FIgURe 7: Acceleration time history (NZROLC.raw, UP, ratl = 1.45, ratr $=2.27$ )

changes in the surrounding environment, and interference, as well as negligence operation of other workers; of course, a large high-frequency "spike" may be caused due to brittle failure of rock beneath the earth's surface close to 
TABLE 3: Records with ratio of PGA to adjacent points greater than 1.1 in New Zealand Mw6.3 earthquake.

\begin{tabular}{|c|c|c|c|c|c|c|c|}
\hline Serial number & Filename & PGA $\left(\mathrm{cm} / \mathrm{s}^{2}\right)$ & Time (s) & LPGA $\left(\mathrm{cm} / \mathrm{s}^{2}\right)$ & Left rate & RPGA $\left(\mathrm{cm} / \mathrm{s}^{2}\right)$ & Right rate \\
\hline 1 & NZCMHS.raw & 344.94 & 14.40 & 329.01 & 1.05 & 290.36 & 1.19 \\
\hline 2 & NZHPSC.raw & 211.59 & 13.75 & 71.65 & 2.95 & 143.39 & 1.48 \\
\hline 3 & NZHVSC.raw & -1646.78 & 12.70 & -1459.21 & 1.13 & -1244.43 & 1.32 \\
\hline 4 & NZLPCC.raw & -893.73 & 14.08 & -726.55 & 1.23 & -881.11 & 1.01 \\
\hline 5 & NZMQZ.raw & 146.18 & 2.45 & 140.13 & 1.04 & 49.14 & 2.98 \\
\hline 6 & NZOXZ.raw & 43.48 & 4.62 & 35.45 & 1.23 & 26.19 & 1.66 \\
\hline 7 & NZHPSC.raw & -288.61 & 13.87 & -236.95 & 1.22 & -216.92 & 1.33 \\
\hline 8 & NZMAYC.raw & 21.21 & 11.15 & 18.71 & 1.13 & 19.57 & 1.08 \\
\hline 9 & NZMQZ.raw & -97.80 & 2.84 & -92.48 & 1.06 & -29.10 & 3.36 \\
\hline 10 & NZOXZ.raw & -54.83 & 4.28 & -40.52 & 1.35 & -41.84 & 1.31 \\
\hline 11 & NZRKAC.raw & 32.24 & 19.32 & 28.74 & 1.12 & 29.61 & 1.09 \\
\hline 12 & NZASHS.raw & -38.18 & 17.19 & -37.04 & 1.03 & -32.18 & 1.19 \\
\hline 13 & NZCBGS.raw & -353.23 & 14.74 & -316.48 & 1.12 & -337.77 & 1.05 \\
\hline 14 & NZCCCC.raw & 787.09 & 13.67 & 669.82 & 1.18 & 716.81 & 1.10 \\
\hline 15 & NZCHHC.raw & 589.61 & 15.10 & 586.08 & 1.01 & 481.80 & 1.22 \\
\hline 16 & NZCMHS.raw & 835.87 & 14.36 & 762.42 & 1.10 & 689.95 & 1.21 \\
\hline 17 & NZDORC.raw & 29.24 & 18.00 & 27.67 & 1.06 & 23.03 & 1.27 \\
\hline 18 & NZDSLC.raw & 32.53 & 16.24 & 26.11 & 1.25 & 31.32 & 1.04 \\
\hline 19 & NZHPSC.raw & 1052.26 & 13.92 & 985.14 & 1.07 & 955.03 & 1.10 \\
\hline 20 & NZHVSC.raw & 2160.54 & 12.75 & 1079.29 & 2.00 & 1932.75 & 1.12 \\
\hline 21 & NZKPOC.raw & -59.39 & 13.73 & -57.27 & 1.04 & -53.19 & 1.12 \\
\hline 22 & NZLINC.raw & 94.04 & 12.93 & 83.32 & 1.13 & 88.77 & 1.06 \\
\hline 23 & NZLPCC.raw & 485.45 & 12.94 & 469.74 & 1.03 & 403.58 & 1.20 \\
\hline 24 & NZMQZ.raw & 72.05 & 2.52 & 33.59 & 2.15 & 10.77 & 6.69 \\
\hline 25 & NZOXZ.raw & 40.74 & 5.01 & 33.58 & 1.21 & 33.49 & 1.22 \\
\hline 26 & NZRKAC.raw & -29.85 & 12.83 & -27.52 & 1.08 & -25.26 & 1.18 \\
\hline 27 & NZROLC.raw & 71.79 & 16.69 & 70.50 & 1.02 & 62.13 & 1.16 \\
\hline 28 & NZSBRC.raw & 22.64 & 16.84 & 22.56 & 1.00 & 16.69 & 1.36 \\
\hline 29 & NZSHFC.raw & 24.87 & 22.41 & 22.20 & 1.12 & 24.79 & 1.00 \\
\hline 30 & NZSMTC.raw & -167.90 & 14.47 & -151.59 & 1.11 & -155.79 & 1.08 \\
\hline 31 & NZSWNC.raw & 68.54 & 17.89 & 60.02 & 1.14 & 61.41 & 1.12 \\
\hline 32 & NZTPLC.raw & 152.56 & 13.01 & 132.30 & 1.15 & 141.82 & 1.08 \\
\hline
\end{tabular}

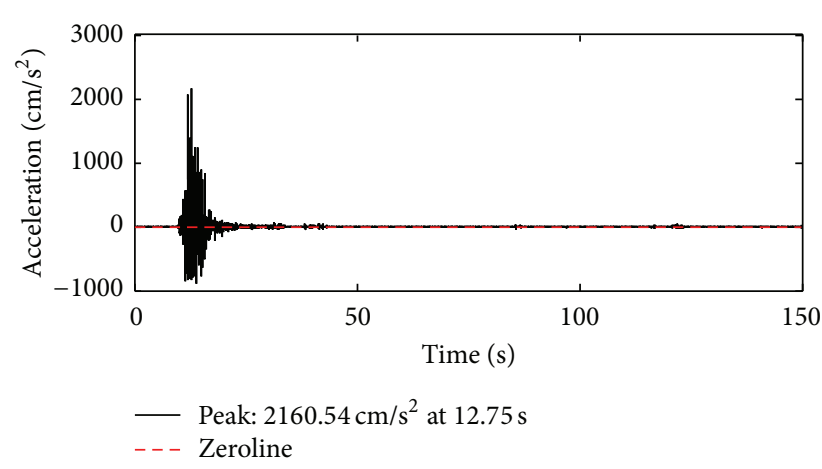

Figure 8: Acceleration time history (NZHVSC.raw, UP, ratl = 2.00, ratr $=1.12$ ).

the station. And this destruction is triggered by the much higher amplitude and a strong stress long cycle velocity pulses. But there is no evidence to prove the causes for

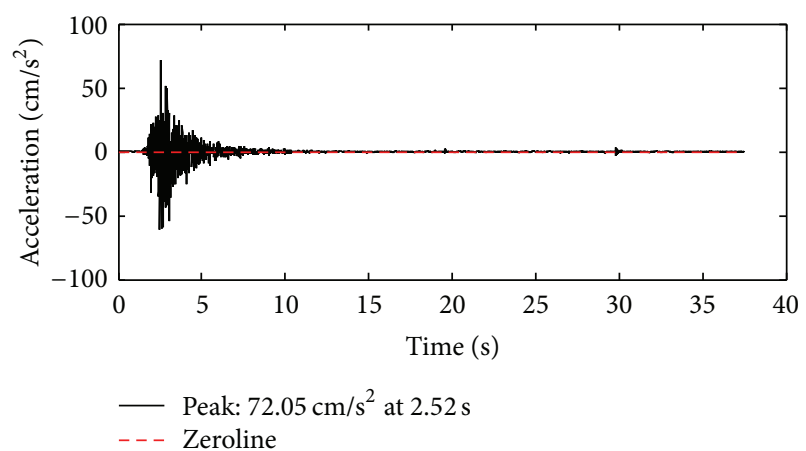

FIGURE 9: Acceleration time history (NZMQZ.raw, UP, ratl = 2.15, ratr $=6.69$ ).

a "spike." Necessary experimental means should be provided to explain the mechanism for "spike" so as to avoid another abnormal strong motion record in the future. 


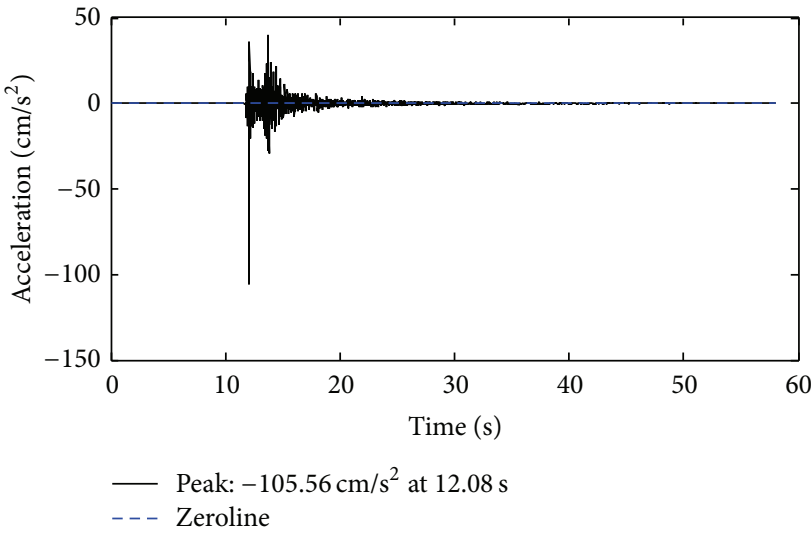

(a) UD direction

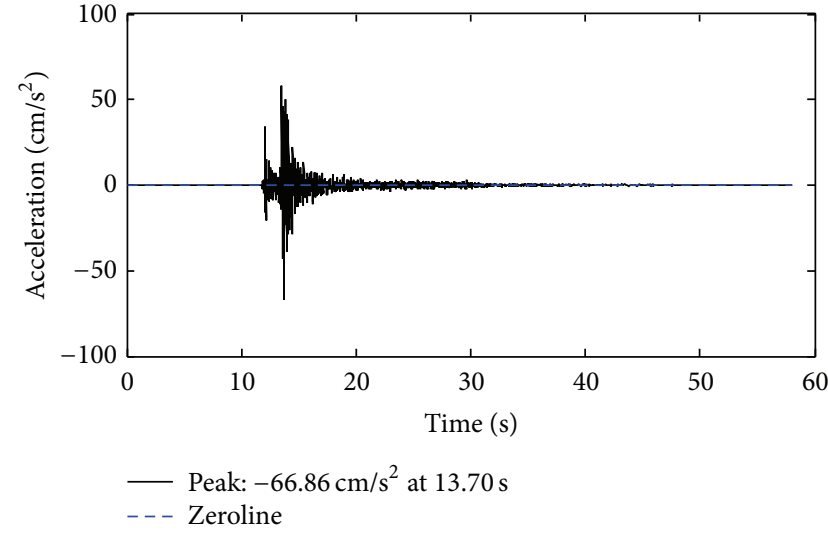

(b) EW direction

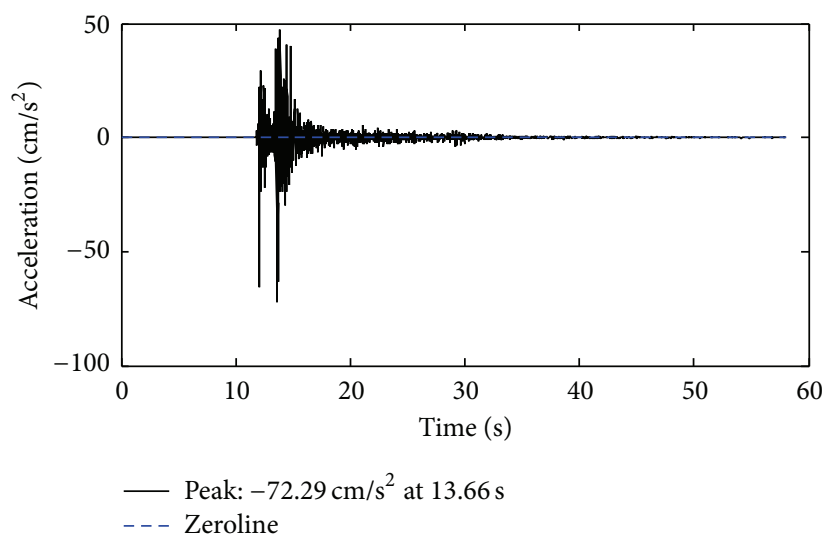

(c) NS direction

Figure 10: Acceleration time history.

2.4. Processing and Analysis of "Spikes" in Strong Motion Records. Currently, two approaches in dealing with such spurious "spikes" are to either remove the "spike" completely or reduce its amplitude to a certain level in coordination with adjacent data points; generally it is adjusted to the average of two adjacent data points [14]. Two strong motion records are selected in the " 5.12 " Wenchuan mainshock both far-fault and near-fault, and two methods are provided to adjust the "spike," the solid line stands for the raw data, the dashed means that this point is set to zero, and the dotted line belongs to the case of the average of the two adjacent data points (see Figure 11). Figure 11(a) shows that it is rich in the long-period components in 032XPX08051214280, and little change happens in the velocity and displacement waveforms; however, the maximum amplitude corresponding to the time history decreases accompanied with the reduction of spike, the position of PGV (peak ground velocity) stays unchanged at $88.000 \mathrm{~s}$, and the position of PGD (peak ground displacement) varies from $41.825 \mathrm{~s}$ to $41.810 \mathrm{~s}$. Fourier amplitude spectrum changes greatly from $2 \mathrm{~s}$ to $6 \mathrm{~s}$ with the predomination period of $0.208 \mathrm{~s}$; however, the peak changes little. Great changes have happened between $0.04 \mathrm{~s}$ and $0.2 \mathrm{~s}$ in absolute acceleration response spectrum, and the maximum amplitude is $4.060 \mathrm{~cm} / \mathrm{s}^{2}, 4.129 \mathrm{~cm} / \mathrm{s}^{2}$ and
$4.930 \mathrm{~cm} / \mathrm{s}^{2}$, respectively. It indicates that the "spike" has little effect on the velocity, displacement, and Fourier amplitude spectrum but for absolute acceleration response spectrum at periods of $0.04-0.2 \mathrm{~s}$. From Figure 11(b), much higher frequency content is relatively abundant for the record of 062WIX080512142802, compared with Figure 11(a); Fourier amplitude spectrum is changing over the entire frequency range and changes little at periods of $0.06-1 \mathrm{~s}$. The absolute acceleration response spectrum has only a modest change between $0.1 \mathrm{~s}-6 \mathrm{~s}$, but the maximum amplitude is all $272.900 \mathrm{~cm} / \mathrm{s}^{2}$ at $0.04 \mathrm{~s}$. So the "spike" only impacts on Fourier amplitude spectrum and the absolute acceleration response spectra greatly.

From two examples illustrated, the adjustment of the PGA can be used to study the impact on relevant parameters, if there is little for the effect, you can use it safely; otherwise, necessary calculations should be carried out to reduce the degree of distortion of data. If it is difficult to identify the "spike," what you should do is to choose other more reasonable data other than the abnormal record in order to ensure the quality of the data, which provides some reference for selecting strong earthquake records in earthquake engineering research. 

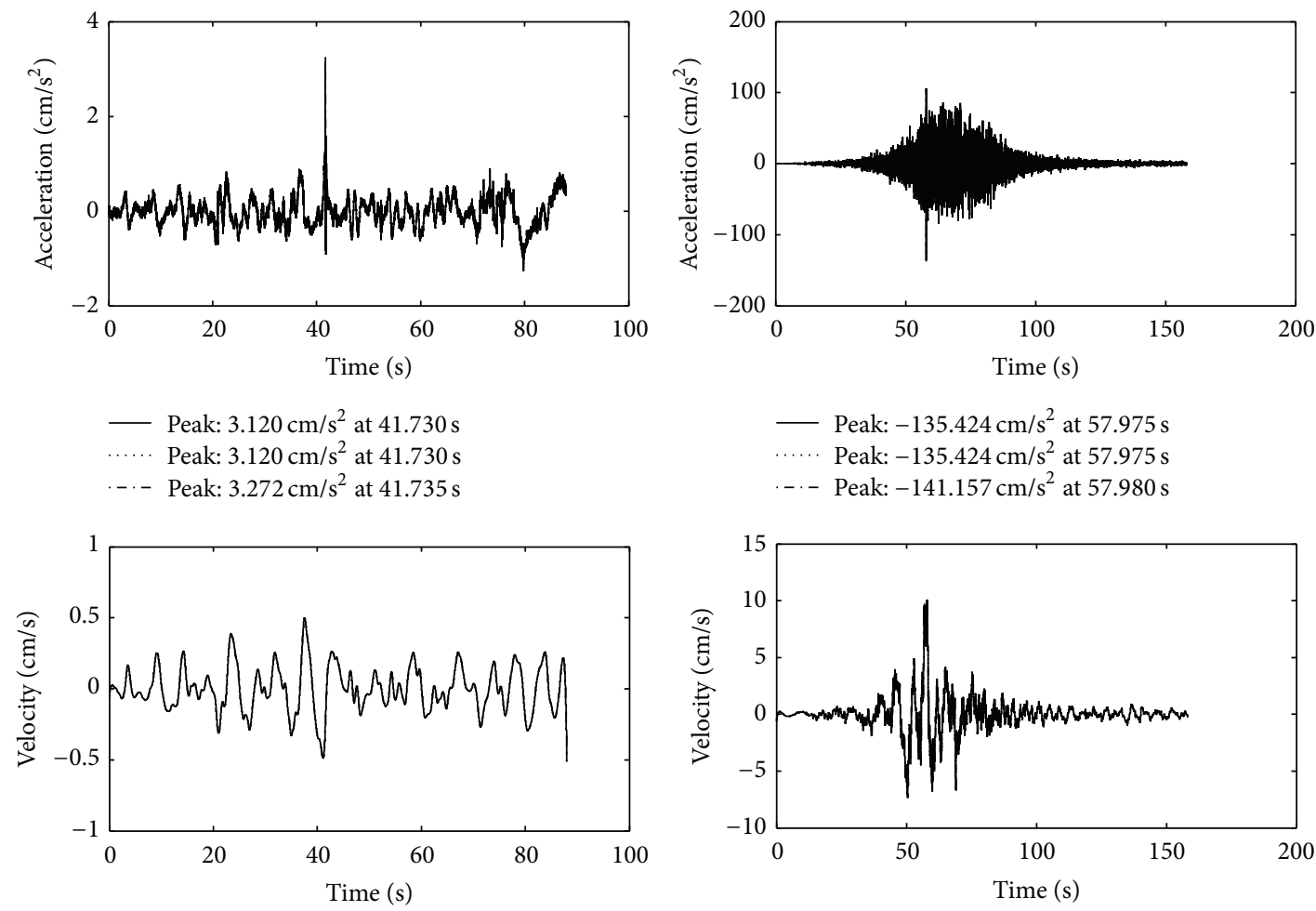

Peak: $-0.512 \mathrm{~cm} / \mathrm{s}^{2}$ at $88.000 \mathrm{~s}$ Peak: $-0.510 \mathrm{~cm} / \mathrm{s}^{2}$ at $88.000 \mathrm{~s}$

. -. Peak: $-0.513 \mathrm{~cm} / \mathrm{s}^{2}$ at $88.000 \mathrm{~s}$

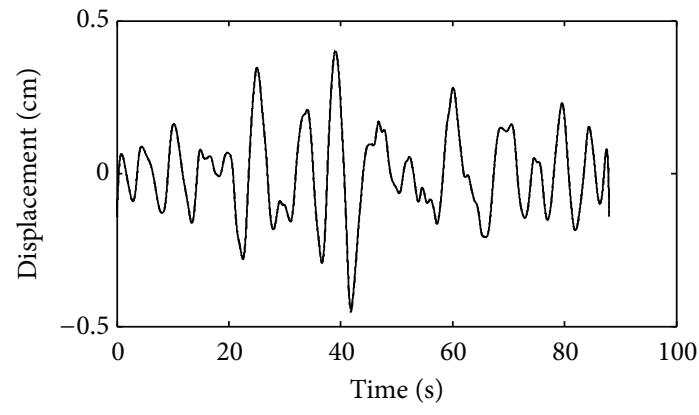

- Peak: $10.036 \mathrm{~cm} / \mathrm{s}^{2}$ at $57.955 \mathrm{~s}$

..... Peak: $10.189 \mathrm{~cm} / \mathrm{s}^{2}$ at $57.955 \mathrm{~s}$

... Peak: $10.383 \mathrm{~cm} / \mathrm{s}^{2}$ at $57.955 \mathrm{~s}$

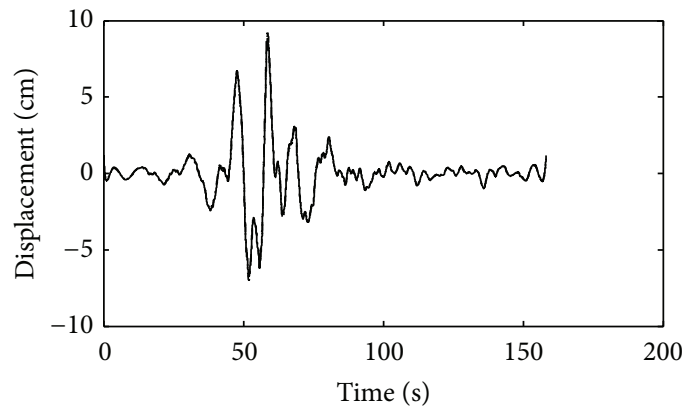

- Peak: $-0.443 \mathrm{~cm} / \mathrm{s}^{2}$ at $41.815 \mathrm{~s}$

… Peak: $-0.447 \mathrm{~cm} / \mathrm{s}^{2}$ at $41.810 \mathrm{~s}$

. . - Peak: $-0.453 \mathrm{~cm} / \mathrm{s}^{2}$ at $41.810 \mathrm{~s}$

- Peak: $8.857 \mathrm{~cm} / \mathrm{s}^{2}$ at $58.610 \mathrm{~s}$

… Peak: $9.117 \mathrm{~cm} / \mathrm{s}^{2}$ at $58.610 \mathrm{~s}$

- - Peak: $9.446 \mathrm{~cm} / \mathrm{s}^{2}$ at $58.605 \mathrm{~s}$
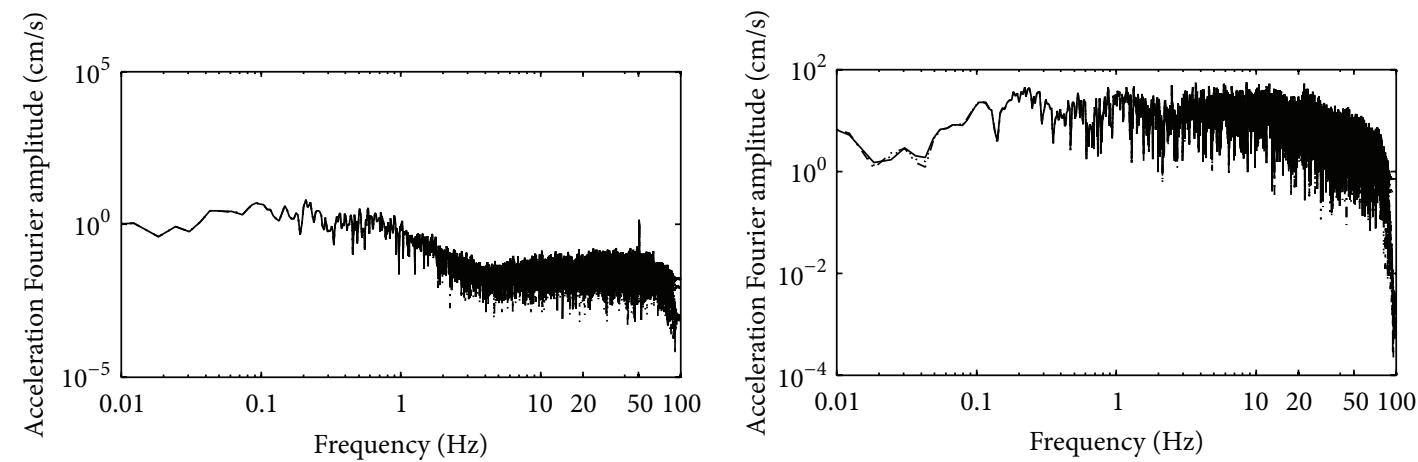

_ Peak: $6.580 \mathrm{~cm} / \mathrm{s}$ at $0.208 \mathrm{~s}$

_ Peak: $55.881 \mathrm{~cm} / \mathrm{s}$ at $8.527 \mathrm{~s}$

..... Peak: $55.569 \mathrm{~cm} / \mathrm{s}$ at $8.527 \mathrm{~s}$

. - . Peak: $55.324 \mathrm{~cm} / \mathrm{s}$ at $3.699 \mathrm{~s}$

FIgure 11: Continued. 


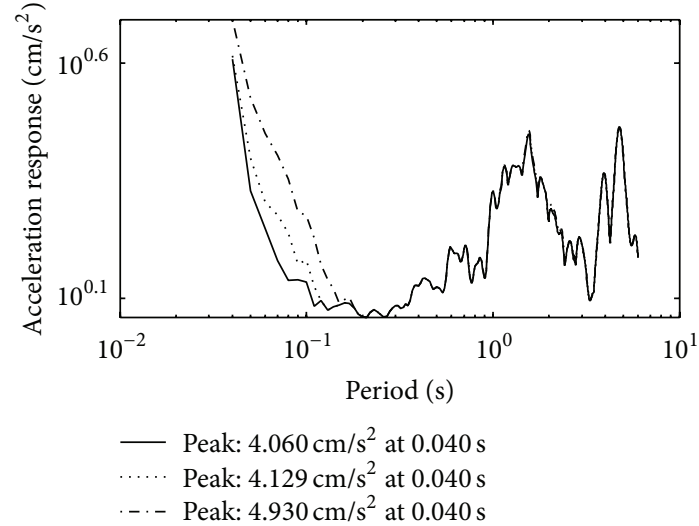

(a) 032XPX080512142803

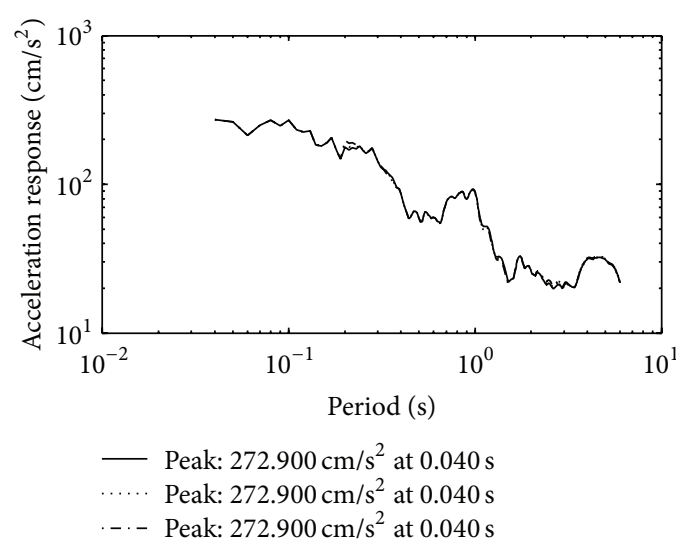

(b) 062WIX080512142802

FIGURE 11: Spikes effect on the time history, the acceleration Fourier amplitude spectrum, and the absolute acceleration response spectrum.

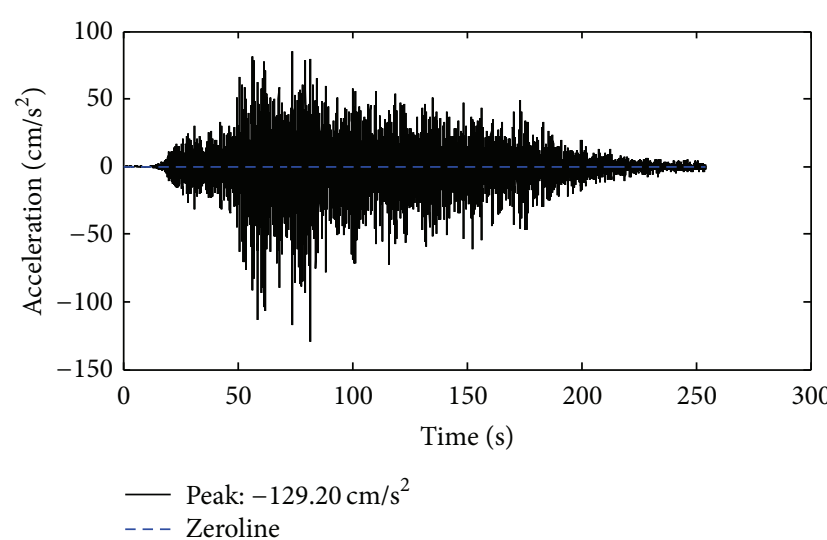

(a) EW direction

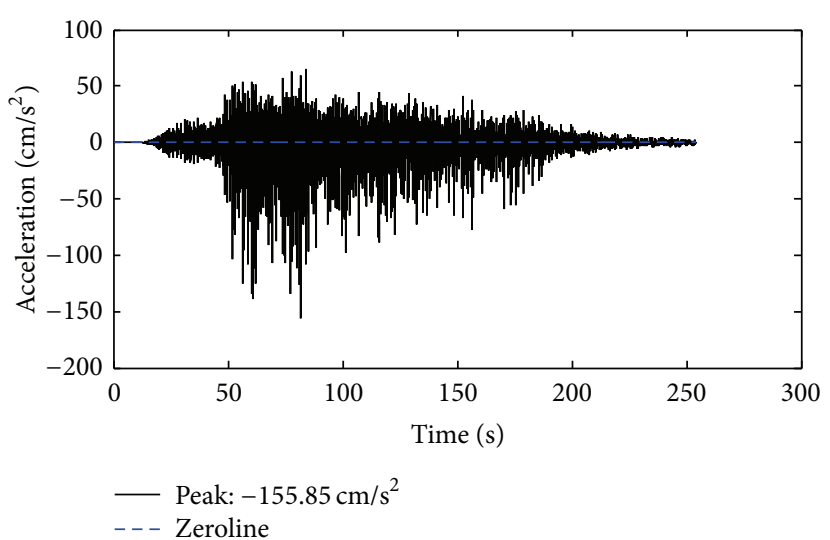

(b) NS direction

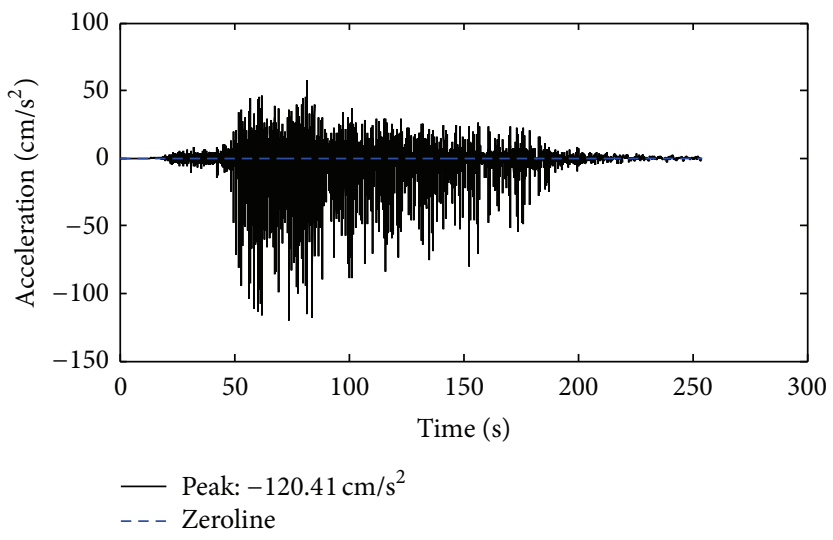

(c) UD direction

FIGURE 12: The three-component acceleration time history.

\section{On Asymmetric Waveform}

"Asymmetric waveform" is another abnormal waveform in strong motion records. This phenomenon occurred in the fixed station named Yibin Gaochang in "5.12" Wenchuan earthquake mainshock [10], as shown in Figure 12, the northsouth and vertical components of the strong motion record become asymmetric. Zhou et al. [2] thinks that the abnormal waveform is caused by the instrument amplification and collision effects.

An earthquake Ms6.3 struck the Christchurch, New Zealand in February 21, 2011. As shown in Figure 13, the vertical components waveform of code named HVSC and PRPC show large asymmetric in amplitude with positive 
TABLE 4: The earthquake information corresponding to strong motion records.

\begin{tabular}{|c|c|c|c|c|c|}
\hline Record number & Magnitude & Longitude $\left(\mathrm{E}^{\circ}\right)$ & Latitude $\left(\mathrm{N}^{\circ}\right)$ & Depth (m) & Epicentral distance $(\mathrm{km})$ \\
\hline 080815010639L2018a & Ms4.2 & 103.50 & 30.98 & 16 & 59.6 \\
\hline 080801163241L2018a & Ms6.0 & 104.85 & 32.02 & 14 & 172.8 \\
\hline 080804174001L2018a & Ms3.3 & 103.36 & 31.37 & 13 & 20.1 \\
\hline 080609152836L2018a & Ms4.5 & 103.93 & 31.31 & 13 & 74.3 \\
\hline 080628022054L2018a & Ms4.2 & 103.45 & 31.43 & 13 & 27.5 \\
\hline 080714001315L2018a & $\mathrm{M}_{\mathrm{L}} 4.0$ & 103.37 & 31.41 & 19 & 20.1 \\
\hline
\end{tabular}

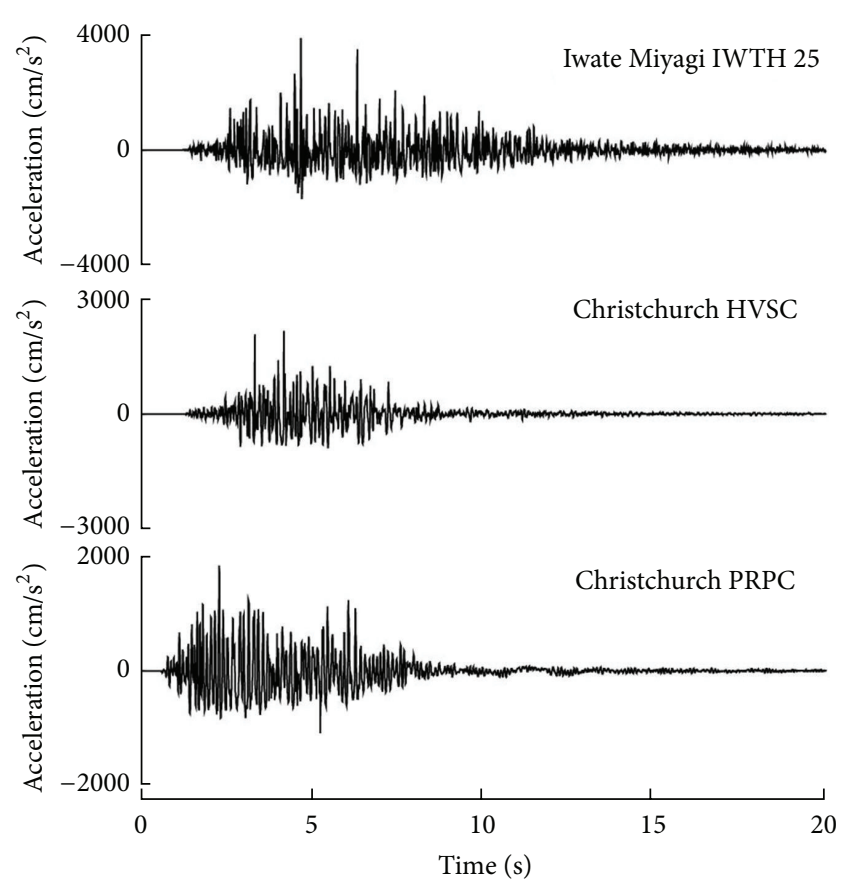

FIGURE 13: Acceleration waveforms of large amplitude.
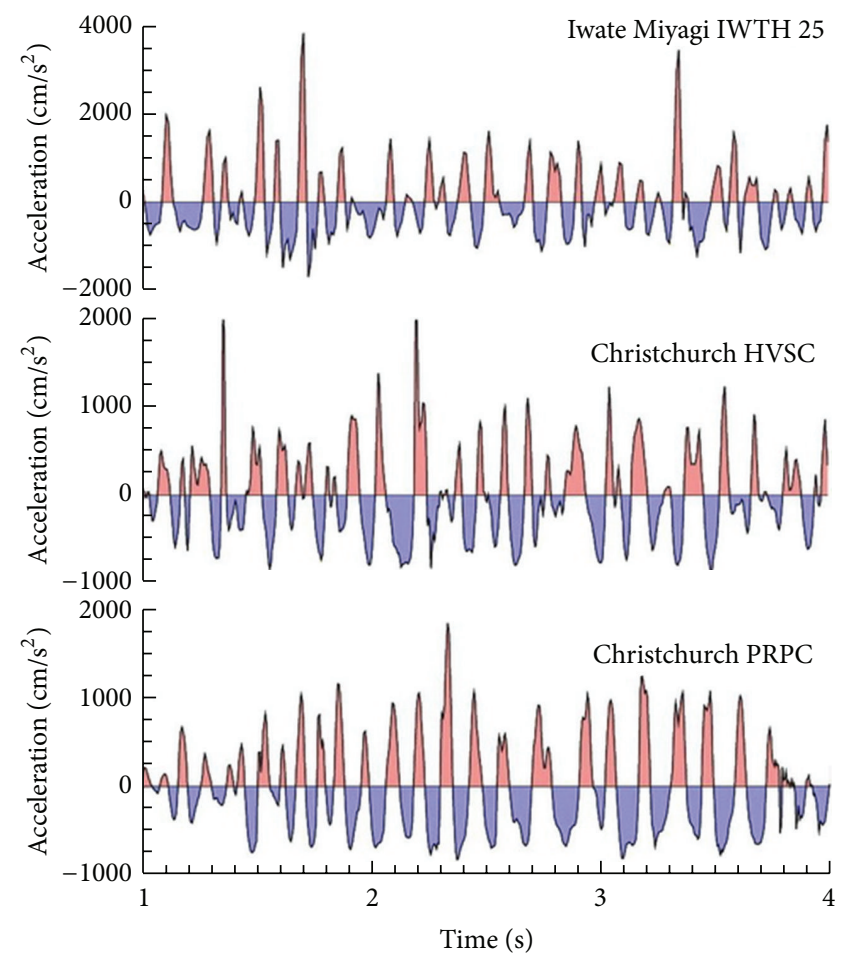

Figure 14: Magnified view of waveforms (0-4s).

the ground shakes up and down. Thus, this asymmetry waveform is attributed to "trampoline effect" [3].

In the aftershocks records of "5.12" Wenchuan earthquake, as shown in Figure 15, six acceleration time histories from the Lixian mobile strong motion station coded L2008 are asymmetry in amplitude, and the velocity and displacement time history are similar, respectively, despite different magnitude and epicenter shown in Table 4; however, asymmetry waveform only appears in the direction of eastwest other than north-south and the vertical direction as shown in Figure 16, which indicates that the most likely thing is to be stuck in instrument failing to record the right strong ground motion waveform.

To correct the asymmetry of a seismic record, taking the vertical component of Yibin Gaochang strong motion record for an example, the Butterworth low-pass filtering with the second order is applied and Figure 17 shows the time history after filtering with the corner frequency of 


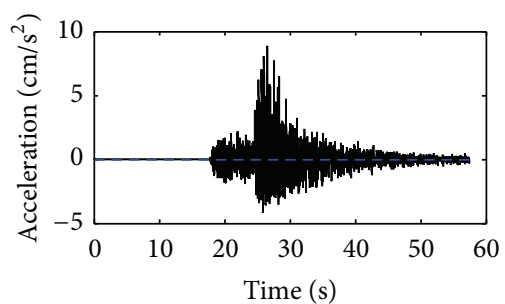

— Peak: $8.91 \mathrm{~cm} / \mathrm{s}^{2}$

- - - Zeroline

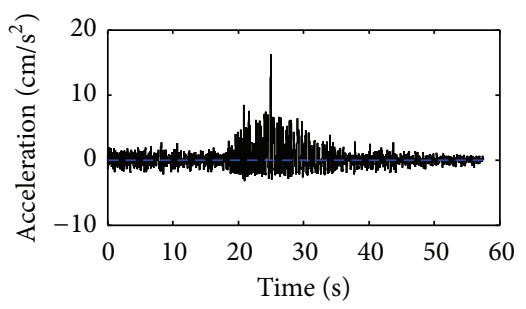

— Peak: $16.23 \mathrm{~cm} / \mathrm{s}^{2}$

- - - Zeroline

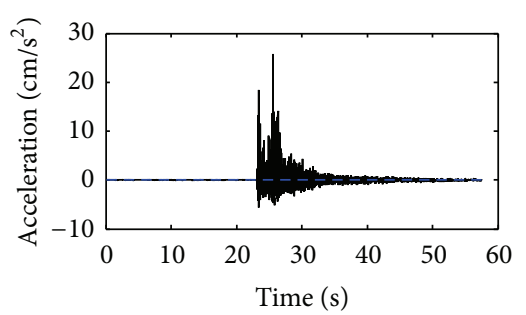

_ Peak: $25.75 \mathrm{~cm} / \mathrm{s}^{2}$

- - - Zeroline

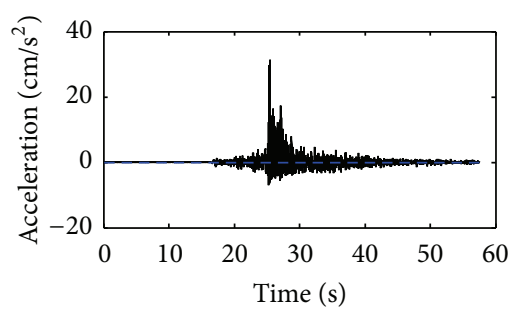

— Peak: $31.35 \mathrm{~cm} / \mathrm{s}^{2}$

- - - Zeroline

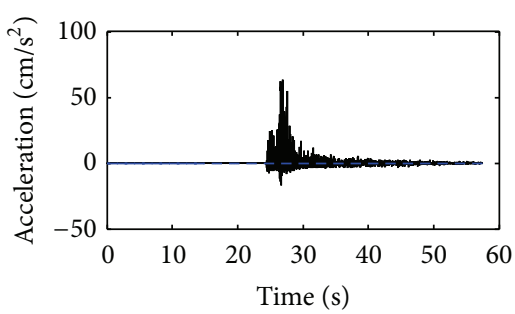

— Peak: $63.70 \mathrm{~cm} / \mathrm{s}^{2}$

- - - Zeroline

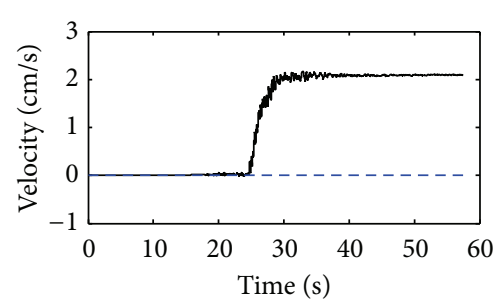

— Peak: $2.18 \mathrm{~cm} / \mathrm{s}$

- - Zeroline

(a) 080815010639L2018a

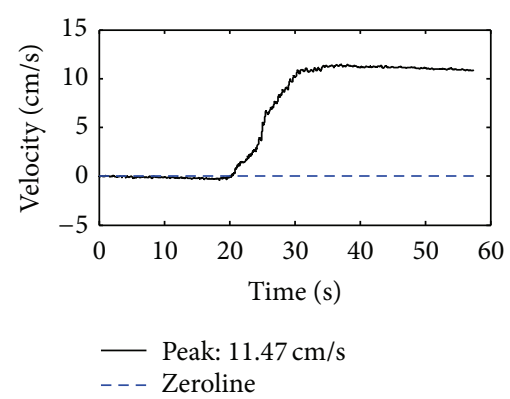

(b) 080801163241L2018a

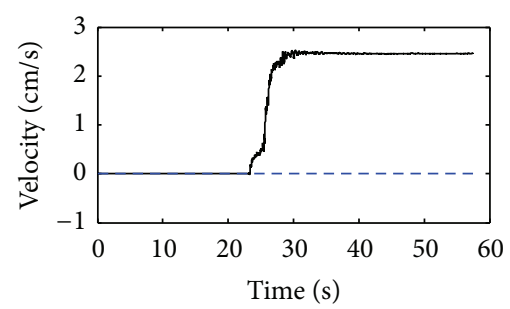

Peak: $2.53 \mathrm{~cm} / \mathrm{s}$

Zeroline

(c) $080804174001 \mathrm{~L} 2018 \mathrm{a}$

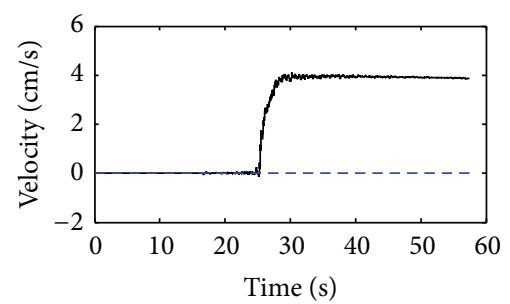

- Peak: $4.10 \mathrm{~cm} / \mathrm{s}$

- - - Zeroline

(d) 080609152836L2018a

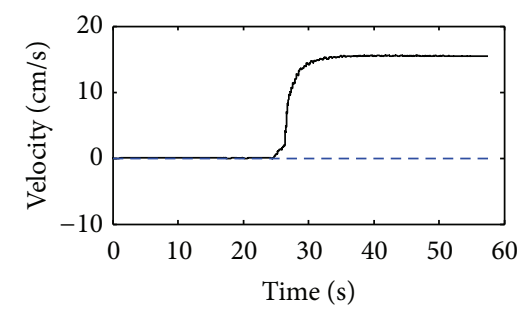

Peak: $15.62 \mathrm{~cm} / \mathrm{s}$

Zeroline

(e) $080628022054 \mathrm{~L} 2018 \mathrm{a}$

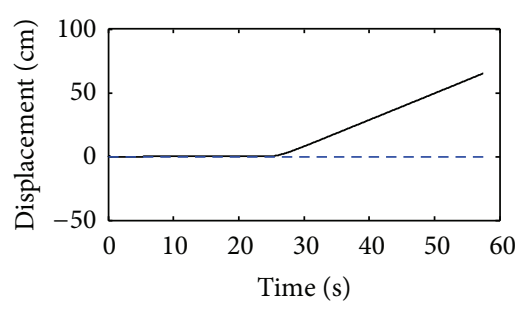

_ Peak: $65.16 \mathrm{~cm}$

- - - Zeroline

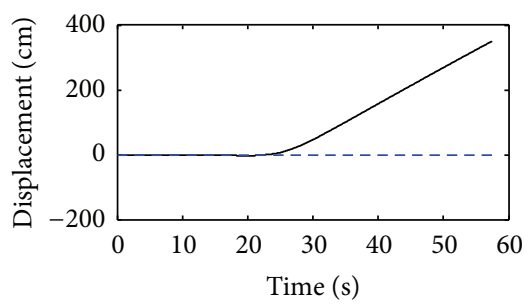

— Peak: $350.36 \mathrm{~cm}$

- - - Zeroline

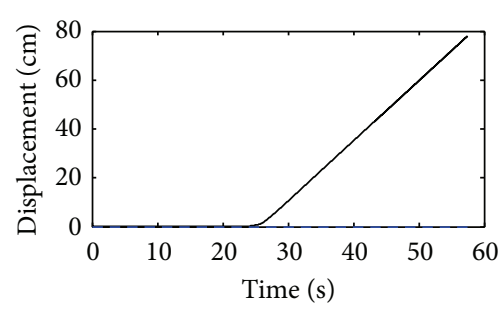

Peak: $78.08 \mathrm{~cm}$

- - - Zeroline

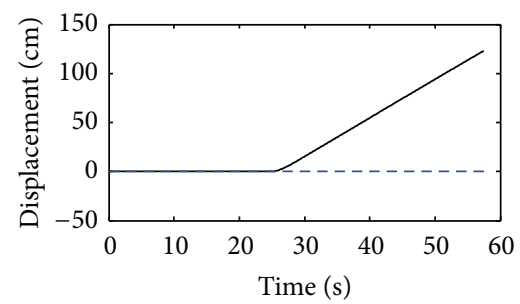

— Peak: $123.03 \mathrm{~cm}$

- - - Zeroline

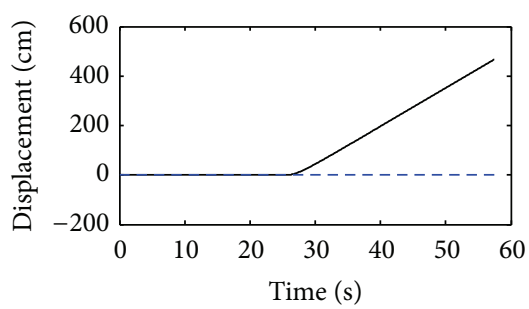

_ Peak: $467.28 \mathrm{~cm}$

- - - Zeroline

FIgURE 15: Continued. 

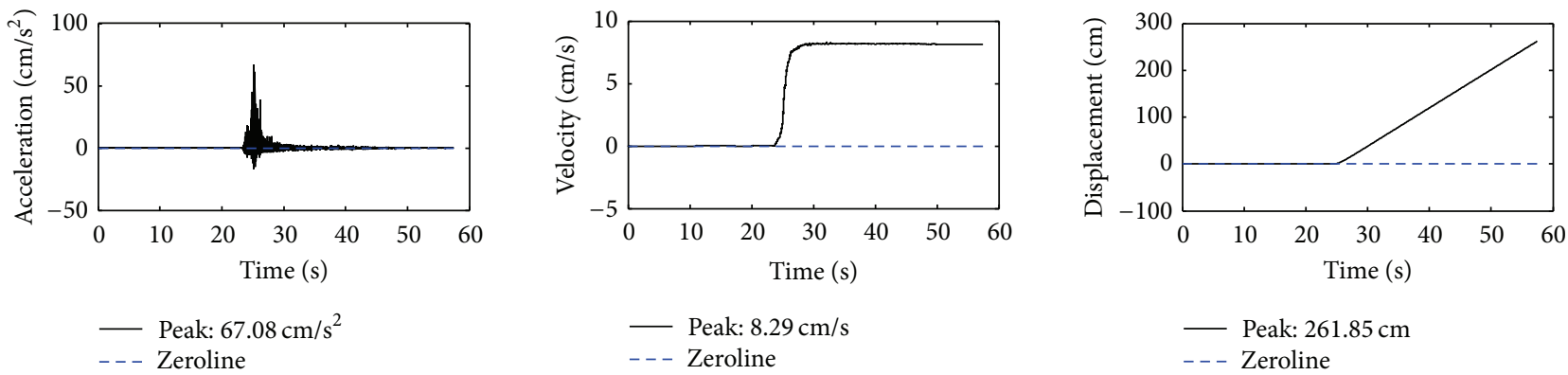

(f) $080714001315 \mathrm{~L} 2018 \mathrm{a}$

FIGURE 15: Acceleration, velocity, and displacement time history.

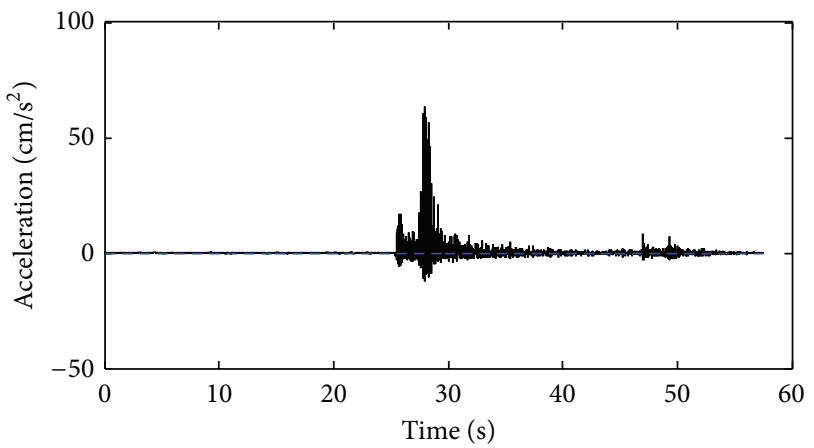

(1) EW direction

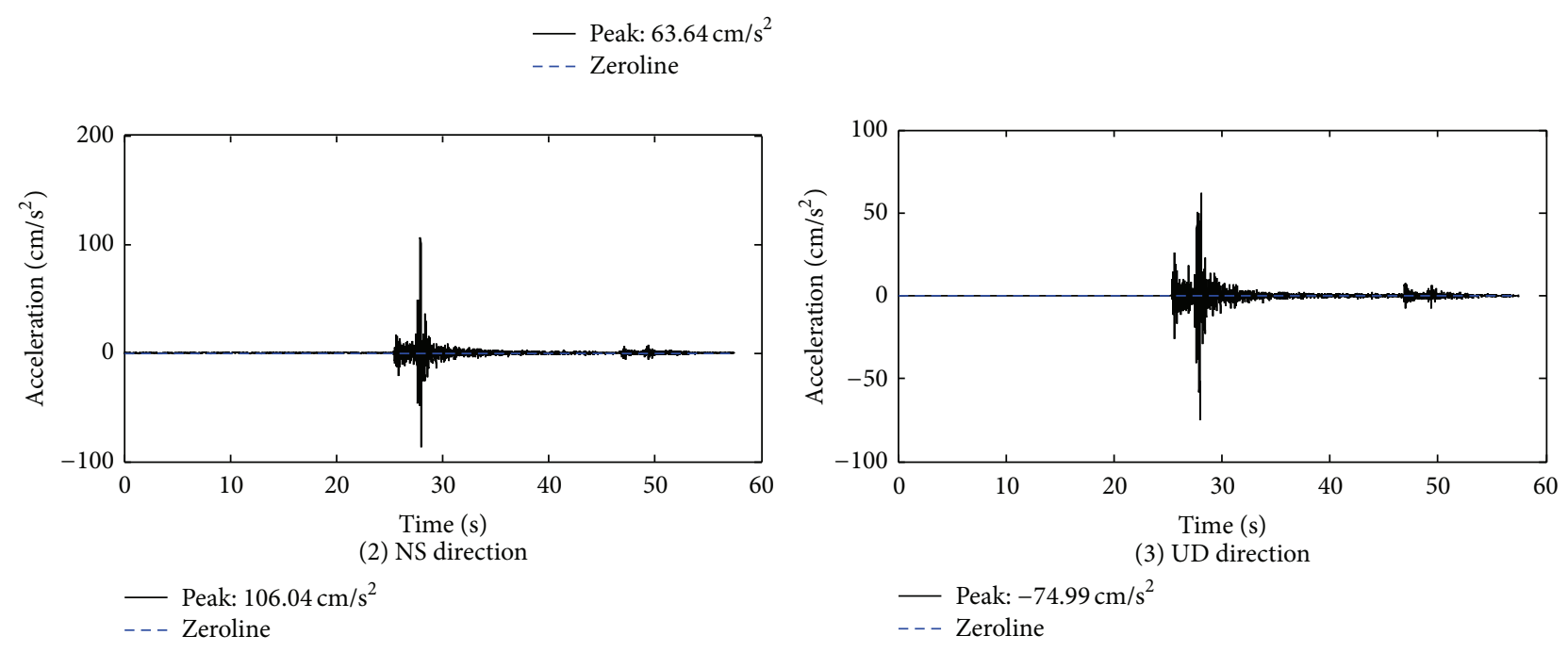

FIGURE 16: Acceleration three-component time history (080628022054L2018).

$80 \mathrm{~Hz}, 60 \mathrm{~Hz}$, and $40 \mathrm{~Hz}$, respectively. Obviously, the waveform tends to become symmetry after filtering; meanwhile, the PGA reduces sharply from $120.41 \mathrm{~cm} / \mathrm{s}^{2}$ to $35.43 \mathrm{~cm} / \mathrm{s}^{2}$. Therefore, we cannot make sure that such filtering is the best correction way for the asymmetry waveform. However, to some extent, filtering can be a correct way for the asymmetry acceleration time history.

In summary, such asymmetric waveform mechanism is of diversity, which consisted of instrument, instrument pier, and trampoline effect. We think that certain number of tests should be carried out to retrieve the abnormal waveforms in order to figure out the exact mechanism. If it is the instrument or the instrument pier that caused the asymmetric waveform, low-pass filtering can be applied to make correction for the asymmetry acceleration time history. However, if asymmetric waveform is produced by trampoline effect, we believe that it is reasonable to be applied to earthquake engineering research. 


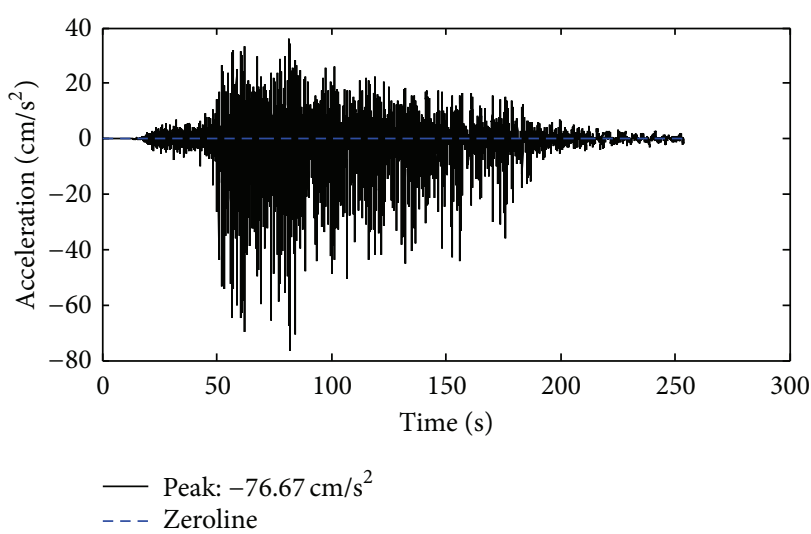

(a) Corner frequency $=80 \mathrm{~Hz}$

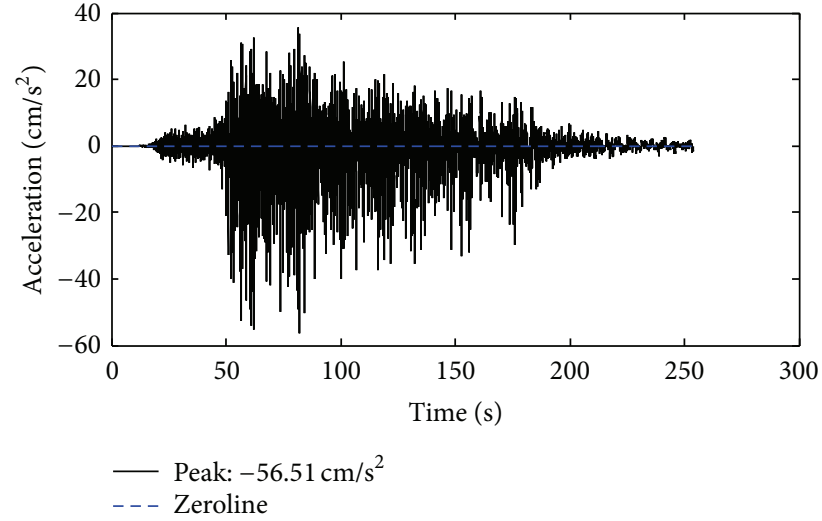

(b) Corner frequency $=60 \mathrm{~Hz}$

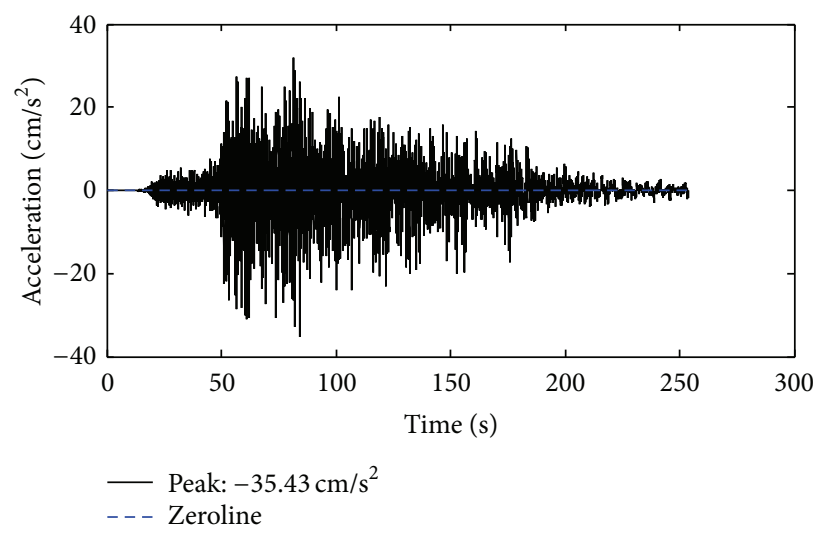

(c) Corner frequency $=40 \mathrm{~Hz}$

Figure 17: Acceleration time history (UD, after low-pass filtering).

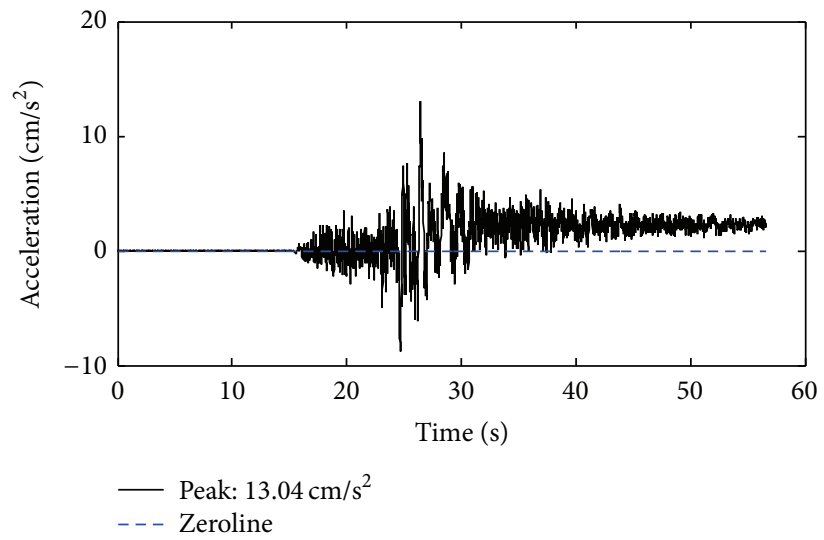

FIGURE 18: Acceleration time history.

\section{On the Obvious Acceleration Baseline Drift}

Under normal circumstances, it is difficult to find the acceleration baseline drift; however, there are some strong motion records with obvious baseline drift. As shown in Figure 18, the strong motion record named 051GYQ080805174903 comes from the fixed station in " 5.12 " Wenchuan earthquake aftershocks [9], and the PGA only reaches $13.04 \mathrm{~cm} / \mathrm{s}^{2}$, but there appears significant baseline shift in the vicinity of $25 \mathrm{~s}$ in original acceleration records. The apparent baseline translational position can be determined by the accumulate adding of acceleration. Figure 19 shows that obvious baseline translational drift begins at $24.575 \mathrm{~s}$. The acceleration time history and response spectra are shown in Figures 20-23 before and after correction. It is not difficult to find that PGA shifts from $13.04 \mathrm{~cm} / \mathrm{s}^{2}$ to $-10.91 \mathrm{~cm} / \mathrm{s}^{2}$, and 


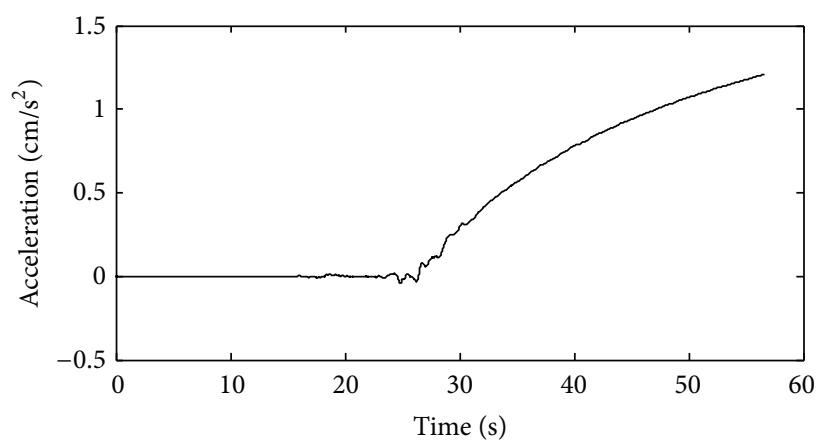

FIgURE 19: Cumulative acceleration time history.

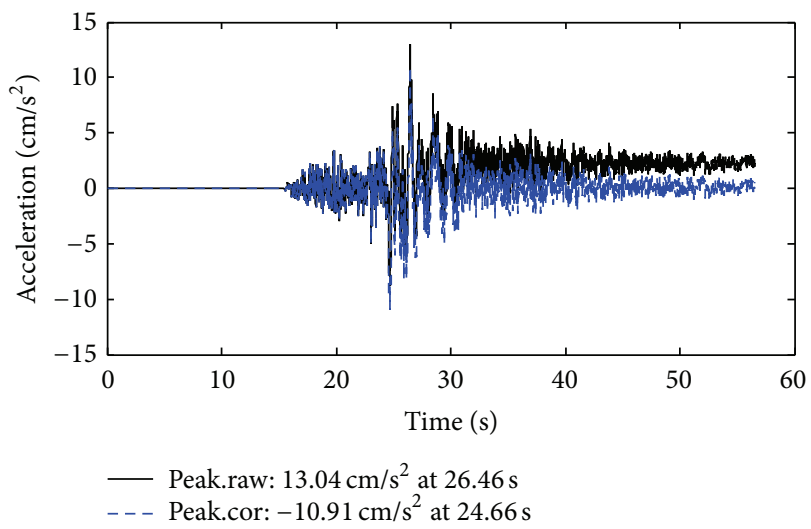

FIgURE 20: Acceleration time history.

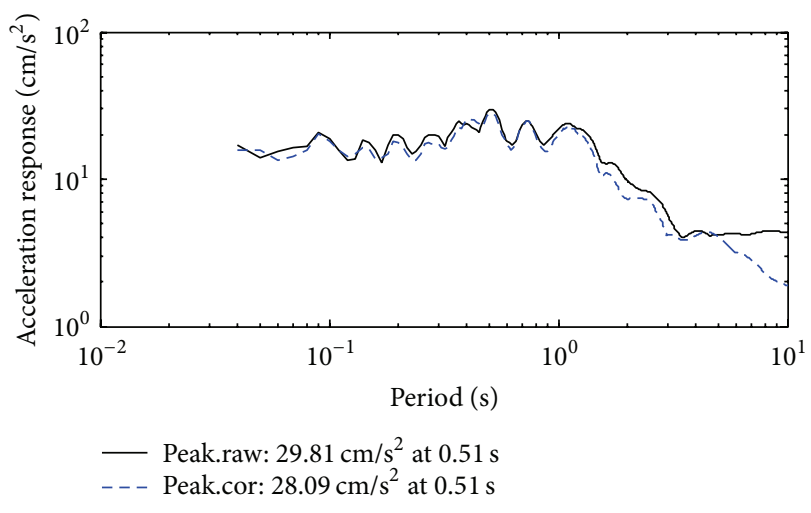

FIgURE 21: Absolute acceleration response spectrum.

the position of PGA is ahead of $1.8 \mathrm{~s}$. And the maximum absolute acceleration response spectrum reduces from $29.81 \mathrm{~cm} / \mathrm{s}^{2}$ to $28.09 \mathrm{~cm} / \mathrm{s}^{2}$, and the decline is only $5.8 \%$; however, the position of the maximum response stays unchanged. The relative velocity response spectrum increases from $4.34 \mathrm{~cm} / \mathrm{s}$ to $4.38 \mathrm{~cm} / \mathrm{s}$, the decline is less than $1 \%$, and the position of the maximum response shifts from $1.3 \mathrm{~s}$ to $1.21 \mathrm{~s}$. In contrast, the maximum response of displacement reduces from $10.94 \mathrm{~cm}$ to $4.80 \mathrm{~cm}$, and the decline reaches $56.1 \%$ to a larger extent; however, the position of the maximum response stays fixed.

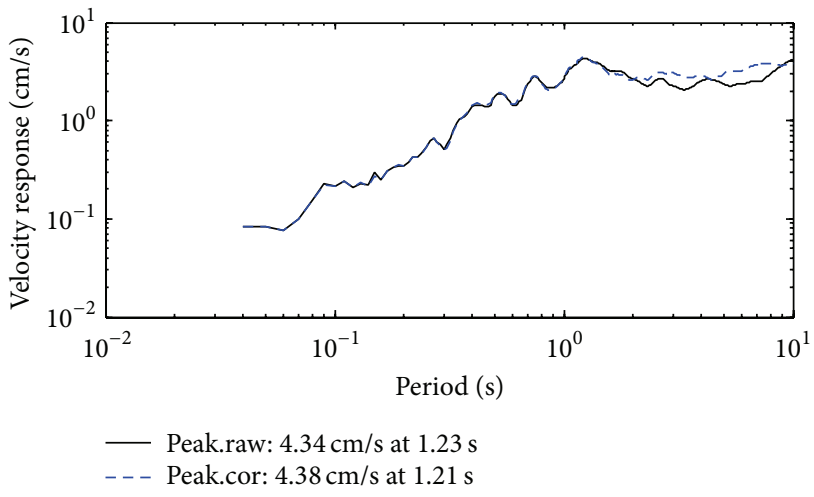

FIGURE 22: Relative velocity response spectrum.

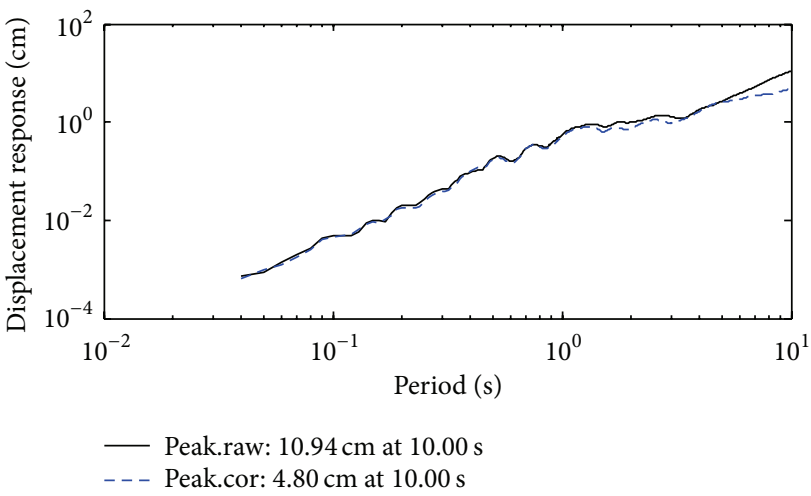

FIGURE 23: Relative displacement response spectrum.

Therefore, it will bring adverse effect on the time history and response spectra with such type of strong motion records uncorrected. The reason for this phenomenon may be due to the stuck sensor or sensor zero offset caused by tilt of the instrument pier during an earthquake.

\section{On Record Separation}

There are some strong motion records with data separation phenomenon in the Lushan earthquake mainshock ground motions. Study shows that a number of data points at 


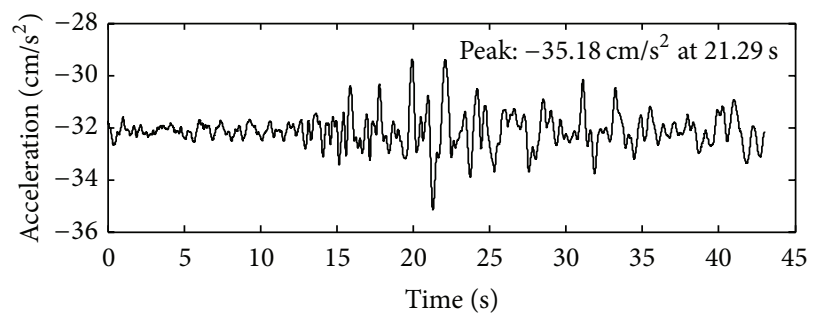

Figure 24: Acceleration time history (1).

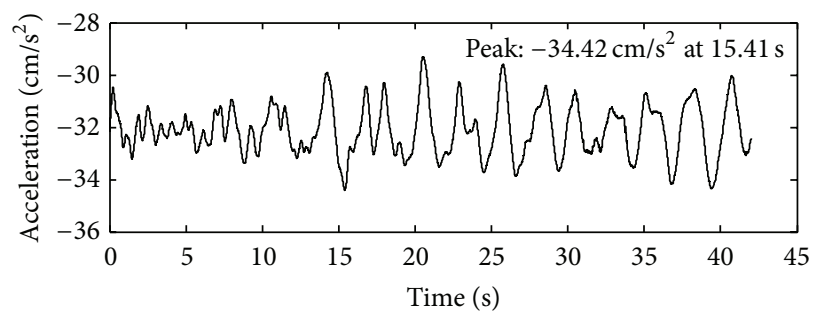

FIGURE 25: Acceleration time history (2).

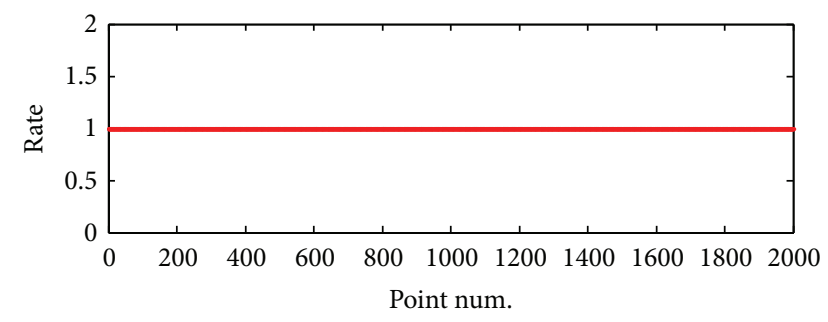

FIGURE 26: Continuous coincidence points.

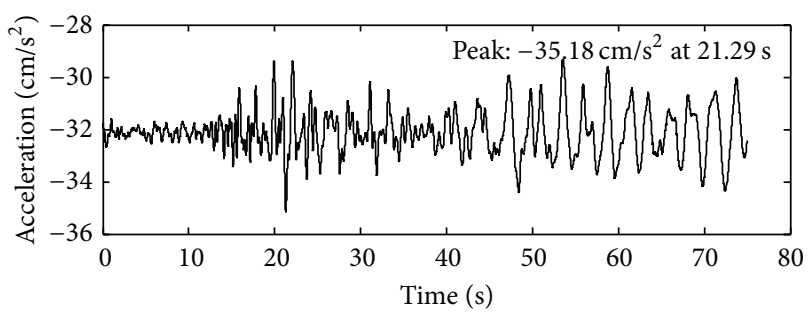

FIGURE 27: Acceleration time history (after splice).

the end of the first data packet are same as the initial part of the second packet data. Therefore, as shown in Figures 2427 Yunnan depot station records [17] in the direction of EW as an example, program codes are wrote to find two packets continuously repeated points. When the tail and head data of data packet consecutive coincide, as is shown in Figure 26, there are 2000 data points with a ratio of 1 , and then the two parts of record are connected together as in Figure 27. We spliced 15 pieces of Lushan earthquake records in this method successfully, as shown in Table 5 . We think that too short preevent time is the cause for isolated records phenomenon. Therefore, sufficient postevent time with 30 seconds should be provided so as to ensure the integrity of the strong motion records.

\section{Discussion and Conclusions}

A series of studies on the simple spike in strong motion records which are selected for PGA greater than 20 gal are carried out. The data includes Chi-Chi, Taiwan earthquake with Mw7.6 in 1999, Christchurch, New Zealand with Mw7.0 and Mw6.3 in 2010 and 2011, respectively. And records with typical spike feature are presented after applying ratio method and the three-component PGA time consistency. Furthermore, the mechanisms of spike are studied in different ways and the effect of different methods for adjusting the spike in the time histories, Fourier amplitude spectrum, and acceleration response spectrum has been presented. Some representative strong motion records with the feature of asymmetric waveform are analyzed and we propose different mechanisms according to various records. We analyze the Lushan earthquake strong motion records data packet isolated phenomenon and give reasonable methods in stitching together. Finally, generation mechanisms and correction method are offered to the strong motion record with clear baseline drift. Studies show that (1) simple "spike" can be relatively easy to identify, and ratio method and threecomponent PGA consistency can determine the complex spike in general, and the appearance of "spike" will affect the time history, frequency spectrum, and response spectrum analysis; (2) the mechanism of "asymmetric waveform" is of diversity, and it is difficult to make reasonable correction; however, to some extent, the Butterworth low-pass filtering can be applied to make correction; (3) two separated packets can be spliced together by finding continuous and repeated data; (4) acceleration records data accumulation at each time point can be used to determine the moment when significant baseline translation process occurs; (5) the wizard waveform 
TABLE 5: Cases for strong motion record splice.

\begin{tabular}{lccc}
\hline Serial number & Record 1 & Record 2 & Continuous coincidence points \\
\hline 1 & 53YSSZ20130420080249-1.001 & 53YSSZ20130420080249-2.001 & 3400 \\
2 & 53YSSZ20130420080249-1.002 & 53YSSZ20130420080249-2.002 & 3400 \\
3 & 53YSSZ20130420080249-1.003 & 53YSSZ20130420080249-2.003 & 3400 \\
4 & 53KXRD20130420080249-1.001 & 53KXRD20130420080249-2.001 & 400 \\
5 & 53KXRD20130420080249-1.002 & 53KXRD20130420080249-2.002 & 400 \\
6 & 53KXRD20130420080249-1.003 & 53KXRD20130420080249-2.003 & 400 \\
7 & 53KXEL20130420080249-1.001 & 53KXEL20130420080249-2.001 & 2000 \\
8 & 53KXEL20130420080249-1.002 & 53KXEL20130420080249-2.002 & 2000 \\
9 & 53KXEL20130420080249-1.003 & 53KXEL20130420080249-2.003 & 2000 \\
10 & 53YJLL20130420080249-1.001 & 53YJLL20130420080249-2.001 & 2500 \\
11 & 53YJLL20130420080249-1.002 & 53YJLL20130420080249-2.002 & 2500 \\
12 & 53YJLL20130420080249-1.003 & 53YJLL20130420080249-2.003 & 2500 \\
13 & 53YJBL20130420080249-1.001 & 53YJBL20130420080249-2.001 & 2800 \\
14 & 53YJBL20130420080249-1.002 & 53YJBL20130420080249-2.002 & 2800 \\
15 & 53YJBL20130420080249-1.003 & 53YJBL20130420080249-2.003 & 2800 \\
\hline
\end{tabular}

directly affects the time history, frequency spectrum, and the response spectra characteristic of acceleration records.

In addition, the mechanism on abnormal waveform has yet been studied based on the theory and experiment and given a more objective approach to promote the further development of strong motion observation discipline, which provides more reliable data to support earthquake engineering research.

\section{Conflict of Interests}

The authors declare that there is no conflict of interests regarding the publication of this paper.

\section{Acknowledgments}

This work was financially supported by Specific Item of Fundamental Scientific Research in Institute of Engineering Mechanics, China Earthquake Administration (2013B20), National Natural Science Foundation of China (51308517), Natural Science Foundation of Heilongjiang Province in China (E2015069), Hei Long Jiang Postdoctoral Foundation in China (LBH-Z13178), Zhejiang Province Natural Science Fund Project of China (LQ12E08006), Postdoctoral fund in China (2014M561516) and Natural Science Foundation of Heilongjiang Province in China (E2015070). The authors pay attribute to Professor Wen Ruizhi, Professor Yu Haiying, and Associate Professor Du Xianfu, who provided a rich set of strong motion records.

\section{References}

[1] K.-L. Wen, H.-Y. Peng, Y.-B. Tsai, and K.-C. Chen, "Why $1 G$ was recorded at TCU129 site during the 1999 Chi-Chi, Taiwan, earthquake," Bulletin of the Seismological Society of America, vol. 91, no. 5, pp. 1255-1266, 2001.

[2] Z. Zhou, R. Wen, D. Lu et al., "Analysis on anomaly of accelerograms in the Wenchuan Earthquake caused by the instrument pier," Journal of Basic Science and Engineering, vol. 18, no. 2, pp. 304-312, 2010.

[3] S. Aoi, T. Kunugi, and H. Fujiwara, "Trampoline effect in extreme ground motion," Science, vol. 322 , no. 5902, pp. 727730, 2008.

[4] J. Douglas, "What is a poor quality strong-motion record?" Bulletin of Earthquake Engineering, vol. 1, no. 1, pp. 141-156, 2003.

[5] J. J. Bommer and J. Douglas, "Processing of European strongmotion records at Imperial College London," in Proceedings of the Workshop on Strong-Motion Record Processing, pp. 39-46, COSMOS, 2004.

[6] D. M. Boore and J. J. Bommer, "Processing of strong-motion accelerograms: needs, options and consequences," Soil Dynamics and Earthquake Engineering, vol. 25, no. 2, pp. 93-115, 2005.

[7] J. Bommer and D. Boore, Guidelines and Recommendations for Strong-Motion Record Processing and Commentary, StrongMotion Record Processing Working Group, 2005.

[8] Ö. Erdoğan, Main seismological features of recently compiled Turkish strong motion database [M.S. thesis], Middle East Technical University, Ankara, Turkey, 2008.

[9] L. Xiaojun, W. Ruizhi, and Y. Haiying, Wenchuan 8.0 Earthquake Aftershock Observation Stations Uncorrected Fixed Acceleration Records, Seismological Press, Beijing, China, 2009.

[10] Earthquake Disaster Prevention and China Seismological Bureau, Wenchuan 8.0 Earthquake Uncorrected Acceleration Records, Seismological Press, Beijing, China, 2008.

[11] W. H. K. Lee, T. C. Shin, K. W. Kuo, and K. C. Chen, CWB Free-Field Strong-Motion Data from the 921 Chi-Chi Earthquake, Volume 1, Digital Acceleration Files on CD-ROM, Seismology Center, Central Weather Bureau, Taipei, Taiwan, 1999.

[12] CESMD internet data report, http://strongmotioncenter.org.

[13] T. Yu, M. Lu, and X. J. Li, "Analysis of strong ground motion characterization in the 2013 Lushan earthquake," Applied Mechanics and Materials, vol. 580-583, pp. 1499-1505, 2014.

[14] K. A. Simpson, The Attenuation of Strong Ground-Motion Incorporating Near-Surface Foundation Conditions, University of London, 1996. 
[15] M. Yamada, J. Mori, and T. Heaton, "The slapdown phase in high-acceleration records of large earthquakes," Seismological Research Letters, vol. 80, no. 4, pp. 559-564, 2009.

[16] T. Tobita, S. Iai, and T. Iwata, "Numerical analysis of nearfield asymmetric vertical motion," Bulletin of the Seismological Society of America, vol. 100, no. 4, pp. 1456-1469, 2010.

[17] S. Li and H. Yu, Lushan 7.0 Earthquake and Aftershock Uncorrected Acceleration Records, Seismological Press, Beijing, China, 2014. 

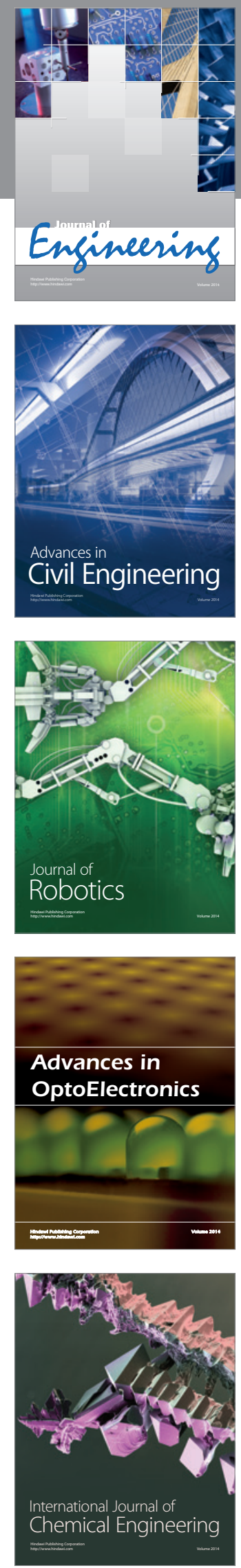

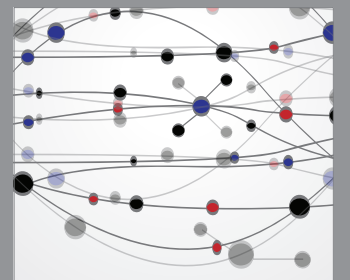

The Scientific World Journal
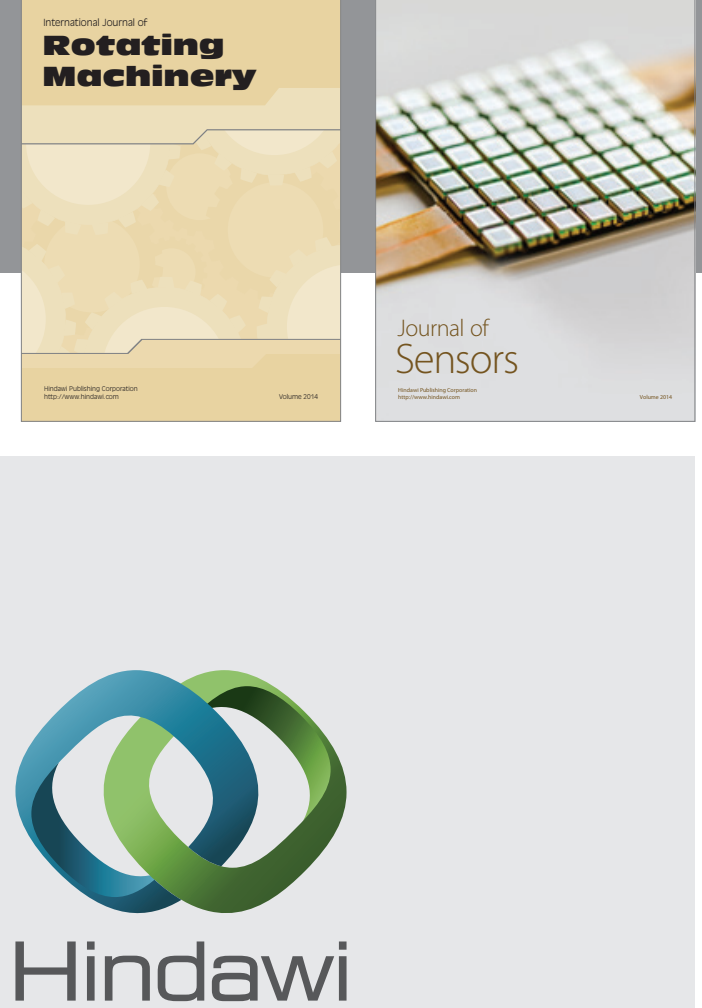

Submit your manuscripts at http://www.hindawi.com
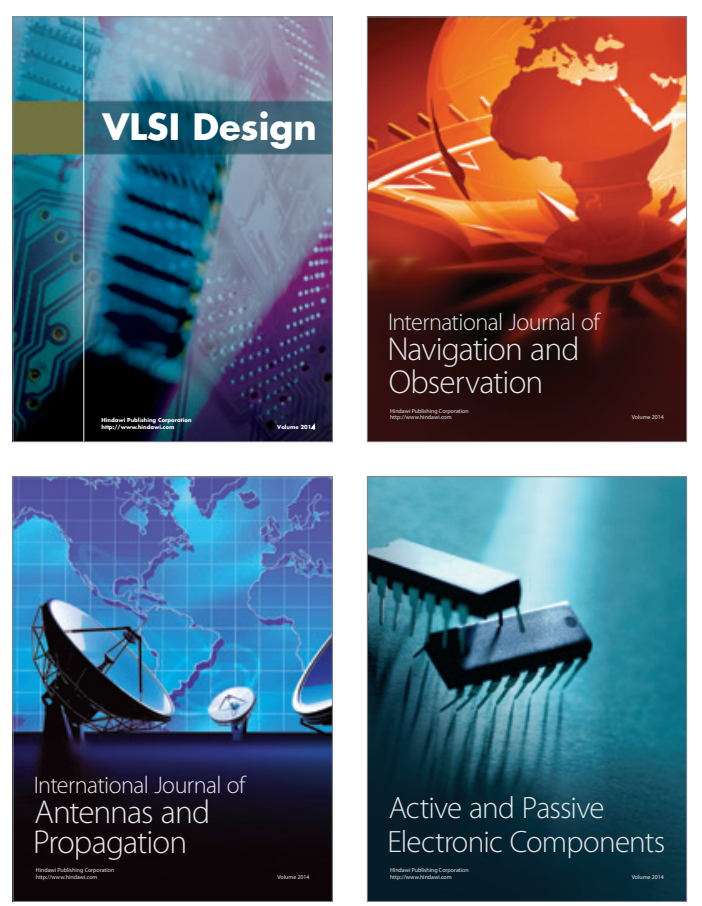
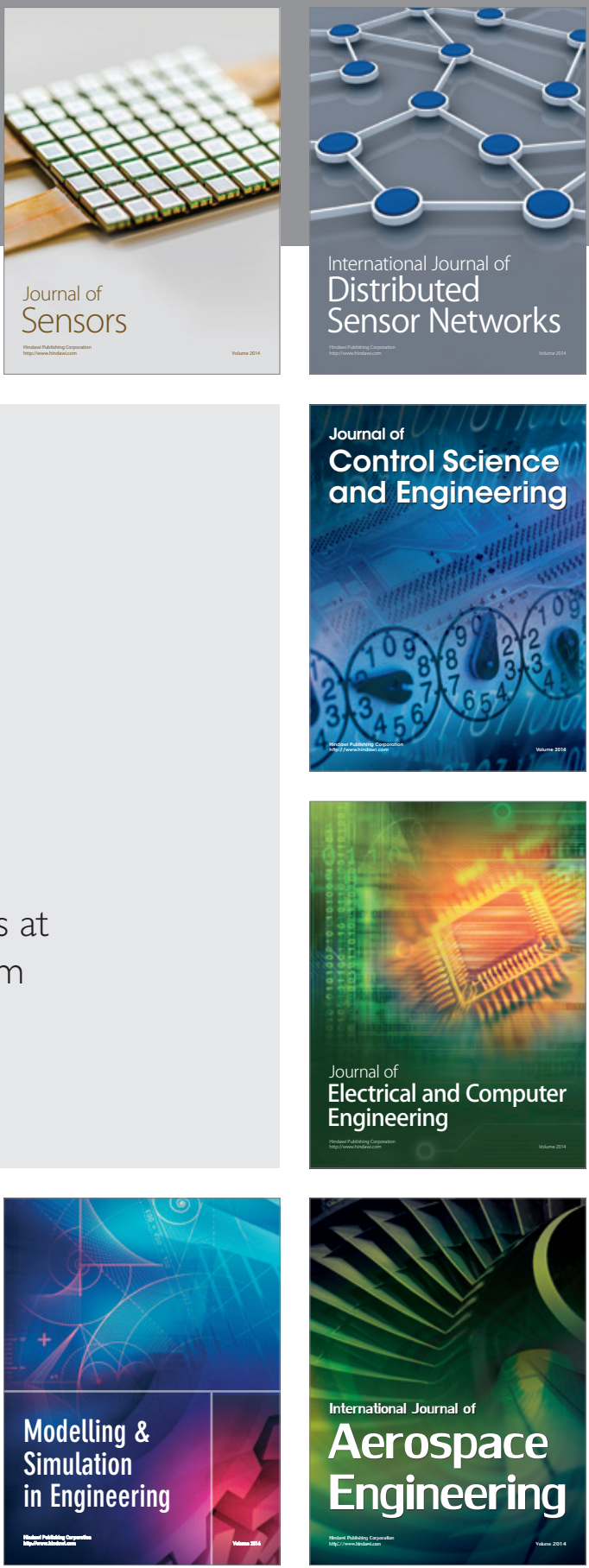

Journal of

Control Science

and Engineering
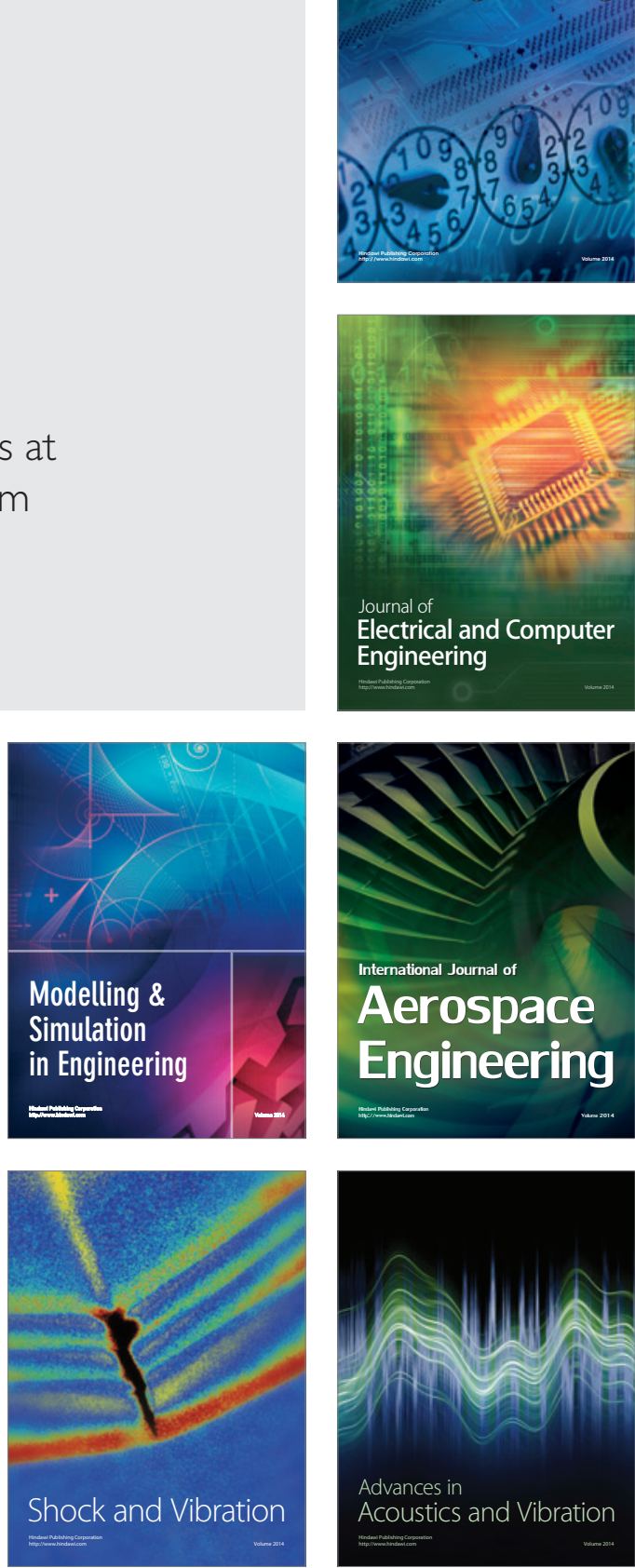